\title{
Two-Dimensional Monthly Average Ozone Balance From Limb Infrared Monitor of the Stratosphere and Stratospheric and Mesospheric Sounder Data
}

\author{
Charles H. Jackman, Richard S. Stolarski, and Jack A. Kaye \\ Atmospheric Chemistry and Dynamics Branch, NASA Goddard Space Flight Center \\ Greenbelt, Maryland
}

\begin{abstract}
Stratospheric constituents are determined by continuity equations including photochemical production and loss as well as the transport and diffusion terms and explicit time variation. Photochemical models self-consistently solve these equations to determine species concentrations. Recent Nimbus 7 measurements give us a first chance to analyze diagnostically the global atmosphere for consistency. We compute the diurnal average photochemical production and loss terms of ozone using monthly and zonally averaged limb infrared monitor of the stratosphere (LIMS) $\mathrm{O}_{3}, \mathrm{H}_{2} \mathrm{O}, \mathrm{HNO}_{3}, \mathrm{NO}_{2}$, and temperature and stratospheric and mesospheric sounder (SAMS) $\mathrm{CH}_{4}$ data. The loss rates of ozone by pure oxygen species, by the nitrogen oxides, and by the hydrogen oxides are calculated along with the production rate of ozone by oxygen photolysis. The other major loss rate for ozone, which is the loss rate by the chlorine family, is calculated from a two-dimensional model including $\mathrm{SAMS}_{\mathbf{C H}}$ measurements and a total $\mathrm{Cl}_{x}$ of $3 \mathrm{ppbv}$ at the stratopause, yielding a $\mathrm{ClO}$ profile in good agreement with balloon measurements. All loss rates of ozone are therefore tied to experimental measurements. Ozone is thought to be in photochemical equilibrium at low latitudes near 2 mbar; however, our calculations show the diurnal average ozone loss to be about $40-60 \%$ higher than the production. Therefore photochemical models using LIMS $\mathrm{H}_{2} \mathrm{O}, \mathrm{HNO}_{3}, \mathrm{NO}_{2}$, and temperature and SAMS $\mathrm{CH}_{4}$ will predict lower ozone concentrations than those measured by LIMS. Uncertainties in this region are a factor of 1.7 with the major contributions coming from the $\mathrm{O}_{3}$ measurements, the calculated photolysis of $\mathrm{O}_{3}$ to $\mathrm{O}\left({ }^{1} D\right)$, and the calculated photolysis for $\mathrm{O}_{2}$.
\end{abstract}

\section{INTRODUCTION}

The balance of ozone production and loss terms in the upper stratosphere has been of concern to atmospheric scientists for many years. It became clear in the mid-1960's that the Chapman mechanism was not sufficient to balance the production of ozone due to the photolysis of molecular oxygen. Hunt [1966] added the $\mathbf{H O}_{x}$ catalytic loss of ozone in a onedimensional calculation that included measurements of $\mathrm{H}_{2} \mathrm{O}$ and $\mathrm{O}_{3}$. Crutzen [1970] noted that the $\mathrm{NO}_{x}$ family also provides a catalytic loss for ozone and included this loss in a one-dimensional calculation of the production and loss terms of ozone using measurements of $\mathrm{H}_{2} \mathrm{O}, \mathrm{O}_{3}$, and $\mathrm{HNO}_{3}$ as well as some calculations of $\mathrm{NO}_{2}$. Four years later it was recognized that the $\mathrm{Cl}_{x}$ family also could have an effect on stratospheric ozone [Stolarski and Cicerone, 1974; Wofsy and $\mathrm{McEl}$ roy, 1974; Crutzen, 1974; Molina and Rowland, 1974]. In 1978, two independent papers were published [Frederick et al., 1978; Johnston and Podolske, 1978] using one-dimensional models with atmospheric measurements which included all four families $\left[\mathrm{O}_{x}, \mathrm{HO}_{x}, \mathrm{NO}_{x}\right.$, and $\left.\mathrm{Cl}_{x}\right]$ that are now believed to be responsible for ozone loss in the stratosphere. These papers both concluded that in the upper stratosphere, where ozone should be in photochemical equilibrium, the ozone loss was higher than the ozone production.

Johnston and Whitten [1973] pioneered the use of instantaneous photochemical rates in order to calculate the production and loss rates of ozone in a two-dimensional form. Solomon et al. [1980] used this method with atmospheric measurements of $\mathrm{O}_{3}$ and $\mathrm{NO}_{2}$ to calculate the loss of ozone due to $\mathrm{O}_{x}$ and $\mathrm{NO}_{x}$ compared to the production of ozone.

This paper is not subject to U.S. copyright. Published in 1986 by the American Geophysical Union.

Paper number 5D0671.
Recently, Crutzen and Schmailzl [1983] computed the twodimensional distributions of ozone production and loss from all four families using available atmospheric measurements including the stratospheric and mesospheric sounder (SAMS) $\mathrm{N}_{2} \mathrm{O}$ and $\mathrm{CH}_{4}$ data, but not including limb infrared monitor of the stratosphere (LIMS) data. One of the conclusions of this study was that the ozone loss was higher than the ozone production in the upper stratosphere.

Building on these previous studies, we do a twodimensional calculation of the production and loss of ozone. Ideally, one needs $\mathrm{O}_{2}, \mathrm{O}_{3}, \mathrm{O}, \mathrm{NO}_{2}, \mathrm{NO}_{3}, \mathrm{H}, \mathrm{OH}, \mathrm{HO}_{2}, \mathrm{ClO}$, temperature, and solar flux in order to calculate the loss and production of ozone (see equations (1)-(6) below). We have available only two-dimensional distribution measurements of $\mathrm{O}_{3}, \mathrm{H}_{2} \mathrm{O}, \mathrm{NO}_{2}, \mathrm{HNO}_{3}, \mathrm{CH}_{4}, \mathrm{~N}_{2} \mathrm{O}$, and temperature, along with solar flux at the top of the atmosphere; thus we must make do with these measurements and use them to derive all other species necessary for the ozone balance calculation. We do a two-dimensional diurnal average calculation using instantaneous rates which demonstrates most of the problems of ozone balance in the stratosphere.

We include the chemistry of $\mathrm{O}_{x}, \mathrm{HO}_{x}, \mathrm{NO}_{x}$, and $\mathrm{Cl}_{x}$ and use monthly and zonally averaged Nimbus 7 limb infrared monitor of the stratosphere (LIMS) $\mathrm{O}_{3}, \mathrm{H}_{2} \mathrm{O}, \mathrm{NO}_{2}, \mathrm{HNO}_{3}$, and temperature (an overview of LIMS data is given by Gille and Russell [1984]), stratospheric and mesospheric sounder (SAMS) $\mathrm{CH}_{4}$ [Jones and Pyle, 1984] data, and solar flux at the top of the atmosphere as described by Guthrie et al. [1984a] (which is taken from Mount and Rottman [1981], D. F. Heath (private communication, 1981), and World Meteorological Organization [1982]). We compare 4 months (November, January, March, and May) of calculations of the loss of ozone divided by the production of ozone. The individual terms going into the production and loss of ozone calculations are also compared for the month of March. The LIMS and 
TABLE 1. Reactions and Their Rates

\begin{tabular}{|c|c|c|}
\hline $\begin{array}{l}\text { Reaction } \\
\text { Number }\end{array}$ & Reaction & Rate Coefficient \\
\hline $\begin{array}{l}\text { (R1) } \\
\text { (R2) } \\
\text { (R3) } \\
\text { (R4) } \\
\text { (R5) } \\
\text { (R6) } \\
\text { (R7) } \\
\text { (R8) } \\
\text { (R9) } \\
\text { (R10) } \\
\text { (R11) } \\
\text { (R12) } \\
\text { (R13) } \\
\text { (R14) } \\
\text { (R15) } \\
\text { (R16) } \\
\text { (R17) } \\
\text { (R18) } \\
\text { (R19) } \\
\text { (R20) } \\
\text { (R21) } \\
\text { (R22) } \\
\text { (R23) } \\
\text { (R24) } \\
\text { (R25) } \\
\text { (R26) } \\
\text { (R27) } \\
\text { (R28) } \\
\text { (R29) } \\
\text { (R30) } \\
\text { (R31) } \\
\text { (R32) } \\
\text { (R33) } \\
\text { (R34) } \\
\text { (R35) } \\
\text { (R36) } \\
\text { (R37) } \\
\text { (R38) } \\
\text { (R39) } \\
\text { (R40) } \\
\text { (R41) } \\
\text { (R42) } \\
\text { (R43) } \\
\text { (R44) } \\
\text { (R45) } \\
\text { (R46) } \\
\text { (R47) } \\
\text { (R48) } \\
\text { (R49) } \\
\text { (R50) } \\
\text { (R51) } \\
\text { (R52) } \\
\text { (R53) } \\
\text { (R54) } \\
\text { (R55) } \\
\text { (R56) } \\
\text { (R57) } \\
\text { (R58) } \\
\text { (R59) } \\
\text { (R60) } \\
\text { (R61) } \\
\text { (R62) } \\
\text { (R63) } \\
\text { (R64) } \\
\text { (R65) } \\
\text { (R62) } \\
\text { (R67) }\end{array}$ & 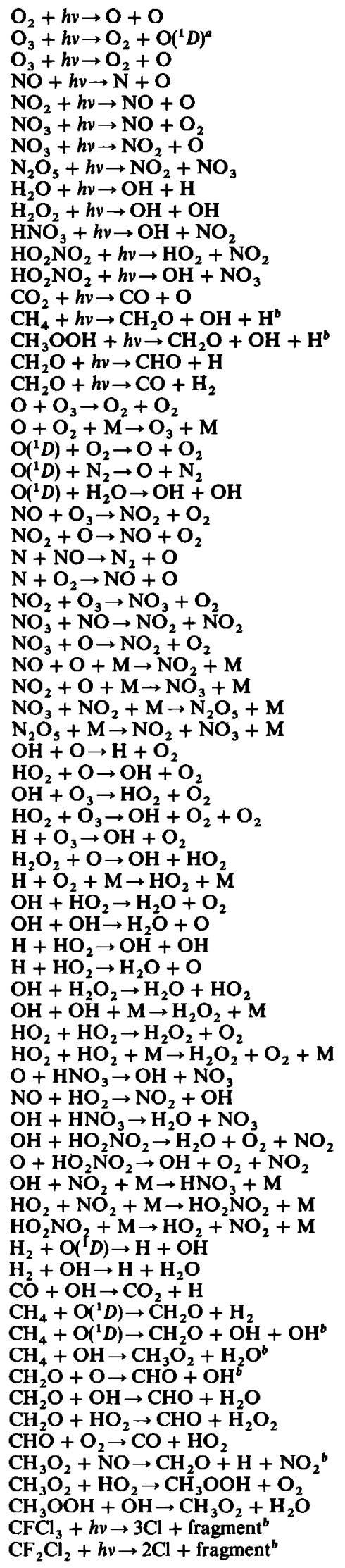 & 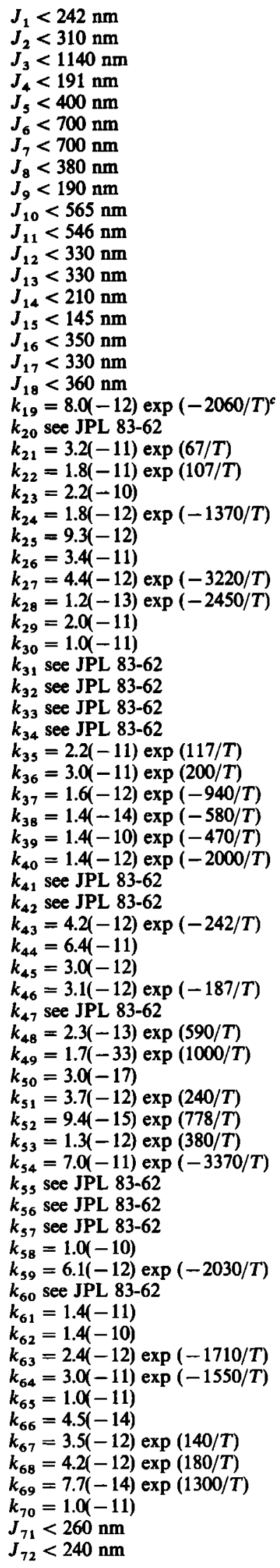 \\
\hline
\end{tabular}


TABLE 1. (continued)

\begin{tabular}{|c|c|c|}
\hline $\begin{array}{l}\text { Reaction } \\
\text { Number }\end{array}$ & Reaction & Rate Coefficient \\
\hline $\begin{array}{l}\text { (R73) } \\
\text { (R74) } \\
\text { (R75) } \\
\text { (R76) } \\
\text { (R77) } \\
\text { (R78) } \\
\text { (R79) } \\
\text { (R80) } \\
\text { (R81) } \\
\text { (R82) } \\
\text { (R83) } \\
\text { (R84) } \\
\text { (R85) } \\
\text { (R86) } \\
\text { (R87) } \\
\text { (R88) } \\
\text { (R89) } \\
\text { (R90) } \\
\text { (R91) }\end{array}$ & 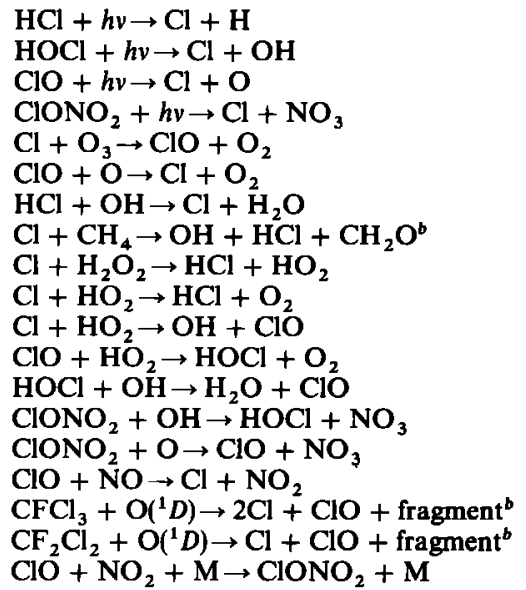 & $\begin{array}{l}J_{73}<220 \mathrm{~nm} \\
J_{74}<420 \mathrm{~nm} \\
J_{75}<310 \mathrm{~nm} \\
J_{76}<450 \mathrm{~nm} \\
k_{77}=2.8(-11) \exp (-257 / T) \\
k_{78}=7.7(-11) \exp (-130 / T) \\
k_{79}=2.8(-12) \exp (-425 / T) \\
k_{80}=9.6(-12) \exp (-1350 / T) \\
k_{81}=1.1(-11) \exp (-980 / T) \\
k_{82}=1.8(-11) \exp (170 / T) \\
k_{93}=4.1(-11) \exp (-450 / T) \\
k_{84}=4.6(-13) \exp (710 / T) \\
k_{85}=3.0(-12) \exp (-150 / T) \\
k_{86}=1.2(-12) \exp (-333 / T) \\
k_{97}=3.0(-12) \exp (-808 / T) \\
k_{98}=6.2(-12) \exp (294 / T) \\
k_{89}=2.3(-10) \\
k_{90}=1.4(-10) \\
k_{91} \text { see JPL } 83-62\end{array}$ \\
\hline
\end{tabular}

Rates correspond to those recommended by DeMore et al. [1983] herein designated as JPL 83-62. Two-body reaction rates have units in $\mathrm{cm}^{3} \mathrm{~s}^{-1}$, three-body values are in $\mathrm{cm}^{6} \mathrm{~s}^{-1}$, and dissociation rates have units in $\mathrm{s}^{-1}$.

${ }^{a}$ Spin conservation is not violated. $O_{2}\left({ }^{1} \Delta\right)$ is assumed to quench to $O_{2}$ rapidly.

${ }^{b}$ Products in these reactions (R15), (R16), (R62), (R63), (R64), (R68), (R71), (R72), (R80), (R89), and (R90) are best guesses which help to speed up the steady state convergence of our two-dimensional model. In particular, for reactions (R62), (R63), (R68), and (R80), we have omitted the short-lived intermediary species $\mathrm{CH}_{3}$ and $\mathrm{CH}_{3} \mathrm{O}$ and replace with species most likely to be end products. Thus the right-hand side of the reaction may not necessarily balance the left-hand side.

'Read $8.0(-12)$ as $8.0 \times 10^{-12}$.

SAMS data are the most complete set of minor constituent measurements in the stratosphere to date; therefore, with these data we obtain a more complete picture of the agreements and disagreements of the ozone balance of the stratosphere. This calculation aids in analyzing our conceptual picture of the photochemistry of the stratosphere.

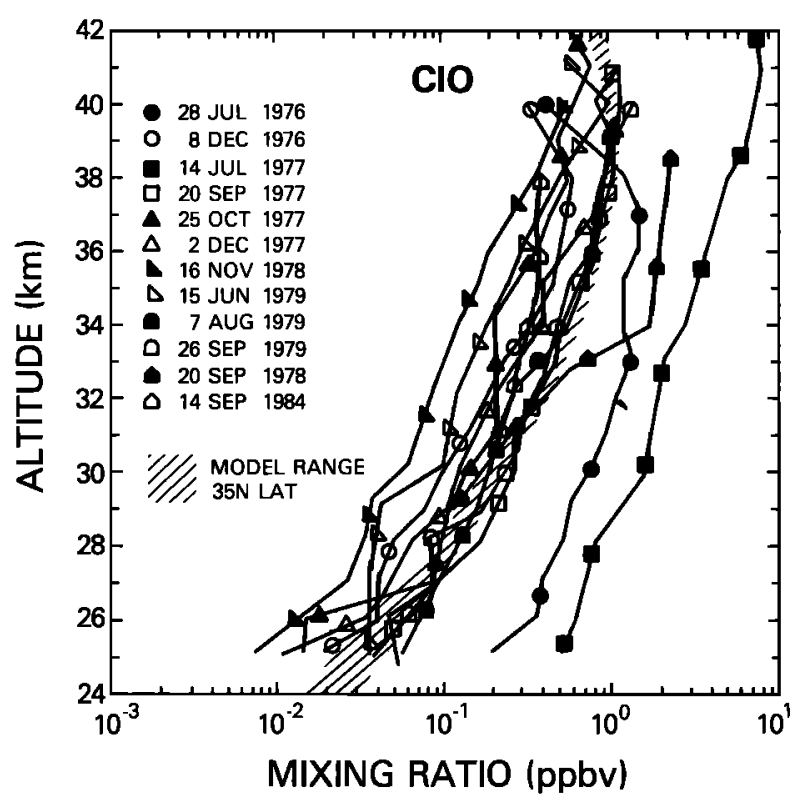

Fig. 1. Observed and calculated vertical mixing ratio profiles for ClO. Observed profiles from Menzies [1979], Anderson et al. [1980], Weinstock et al. [1981], and Brune et al. [1985]. Model range for $35^{\circ} \mathrm{N}$ with total $\mathrm{Cl}_{x}$ set at $3 \mathrm{ppbv}$ in the middle to upper stratosphere.

\section{Production and Loss Terms for Ozone}

We calculate the production and loss terms in a manner similar to that used by Johnston and Podolske [1978]. Since we are mainly concerned with the stratosphere, a number of the terms involved in the production and loss of ozone can be neglected in the present analysis.

The production of ozone, $P$, in the stratosphere is given by

$$
P=2 J_{1}\left[\mathrm{O}_{2}\right]
$$

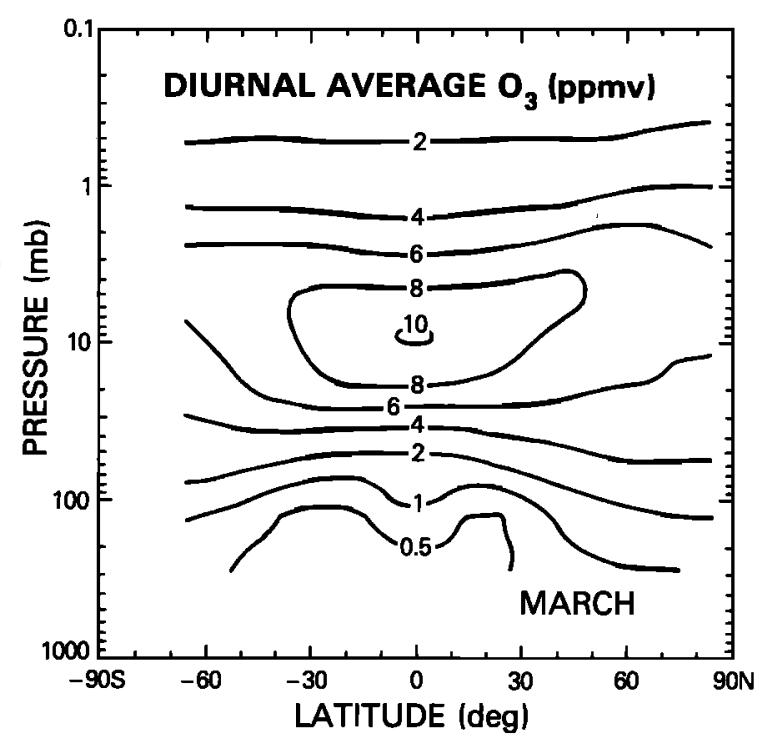

Fig. 2. Monthly zonally average LIMS ozone (in ppmv) for March used in the total ozone loss computation. The values were computed from LIMS data using a diurnal average approximation. 


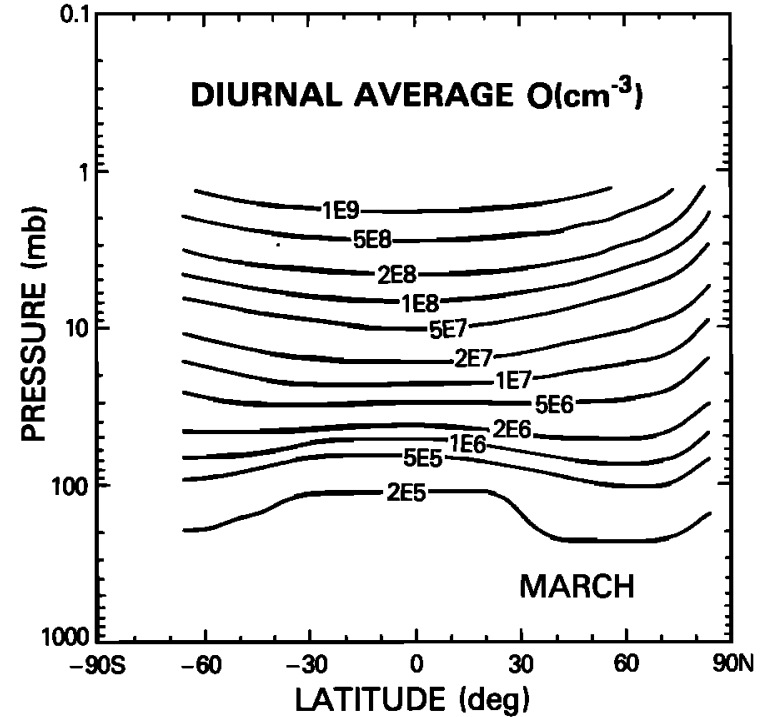

Fig. 3. Monthly zonally average atomic oxygen (in $\mathrm{cm}^{-3}$ ) for March used in the total ozone loss computation.

The photodissociation rate for molecular oxygen is represented by $J_{1}$ (see (R1) in Table 1). Actually, when we compute either the production or the loss of ozone we really are computing the production or the loss of odd oxygen, which is the sum of $\mathrm{O}_{3}, O\left({ }^{3} P\right)$, and $\mathrm{O}\left({ }^{1} D\right)$. In the stratosphere, odd oxygen is primarily in the form of $\mathrm{O}_{3}$. The $P$ results in the production of two oxygen atoms which very quickly combine with a molecule of oxygen and a third body to form ozone (see (R20) in Table 1).

The loss of ozone, $L$, in the stratosphere is given by

$$
L=L\left(\mathrm{O}_{x}\right)+L\left(\mathrm{NO}_{x}\right)+L\left(\mathrm{HO}_{x}\right)+L\left(\mathrm{Cl}_{x}\right)
$$

We take $L\left(\mathrm{O}_{x}\right), L\left(\mathrm{NO}_{x}\right)$, and $L\left(\mathrm{HO}_{x}\right)$ directly from equation (88) of Johnston and Podolske [1978]. The $L\left(O_{x}\right)$ is repre-

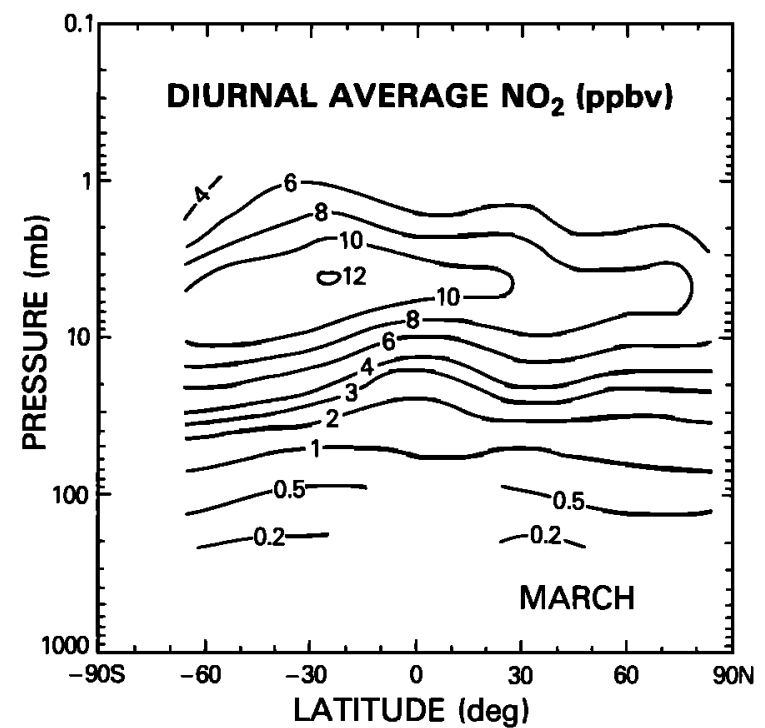

Fig. 4. Monthly zonally average LIMS nitrogen dioxide (in ppbv) for March used in the total ozone loss computation. The values were computed from LIMS data using a diurnal average approximation.

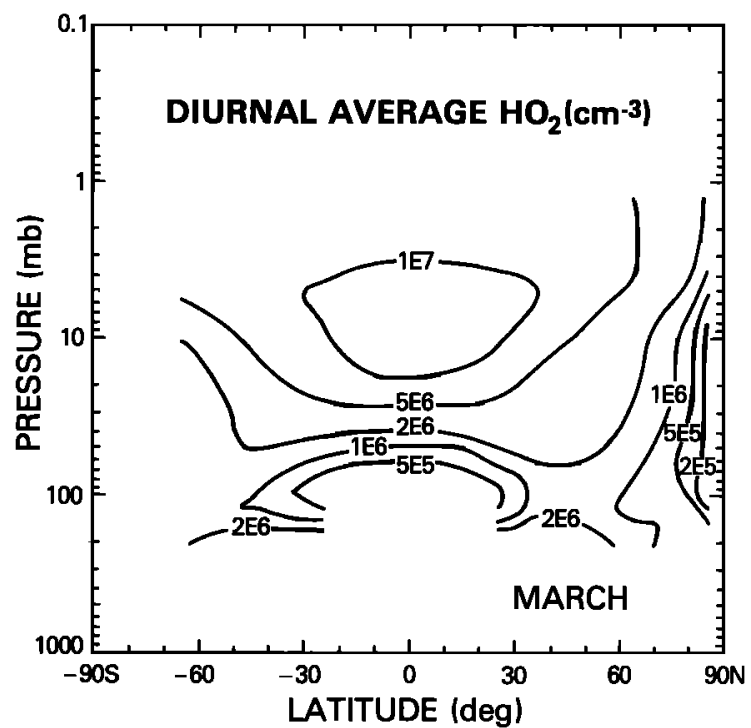

Fig. 5. Monthly zonally average $\mathrm{HO}_{2}$ (in $\mathrm{cm}^{-3}$ ) for March used in the total ozone loss computation.

sentative of the so-called "Chapman mechanism" and is given by

$$
L\left(\mathrm{O}_{x}\right)=2 k_{19}[\mathrm{O}]\left[\mathrm{O}_{3}\right]
$$

The $L\left(\mathrm{NO}_{x}\right)$ is representative of the ozone loss due to $\mathrm{NO}_{x}$ species. It is written as

$$
L\left(\mathrm{NO}_{x}\right)=2 k_{25}\left[\mathrm{NO}_{2}\right][\mathrm{O}]+2 J_{6}\left[\mathrm{NO}_{3}\right]
$$

The $L\left(\mathrm{HO}_{x}\right)$ is the most complex to represent. Many representations have been used but we have chosen that of Johnston and Podolske, given by

$$
\begin{aligned}
& L\left(\mathrm{HO}_{x}\right)=2\left(k_{36}\left[\mathrm{HO}_{2}\right][\mathrm{O}]+k_{38}\left[\mathrm{HO}_{2}\right]\left[\mathrm{O}_{3}\right]\right. \\
& \left.+k_{39}[\mathrm{H}]\left[\mathrm{O}_{3}\right]+k_{42}[\mathrm{OH}]\left[\mathrm{HO}_{2}\right]+k_{48}\left[\mathrm{HO}_{2}\right]\left[\mathrm{HO}_{2}\right]\right)
\end{aligned}
$$

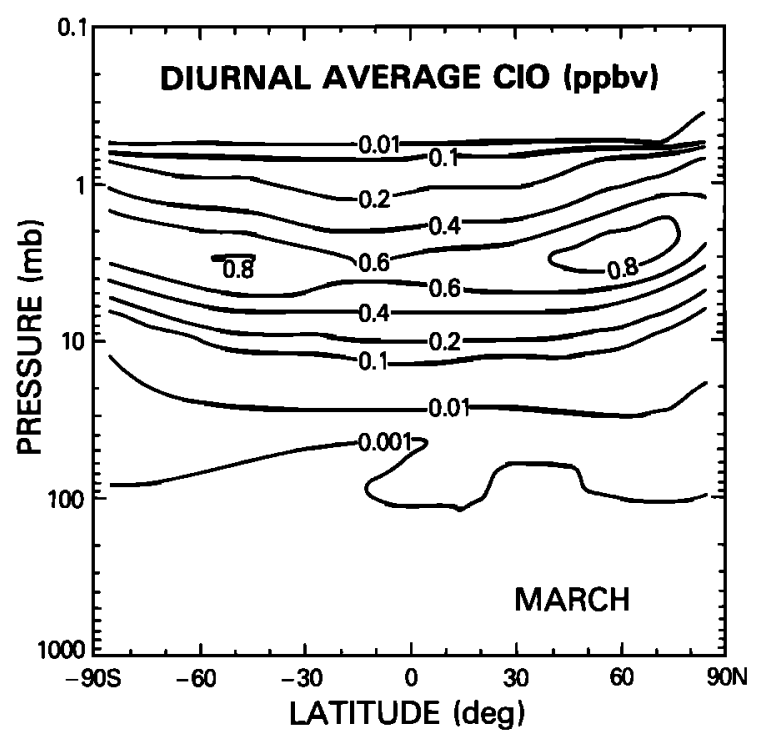

Fig. 6. Monthly zonally average $\mathrm{ClO}$ (in ppbv) for March used in the total ozone loss computation. 

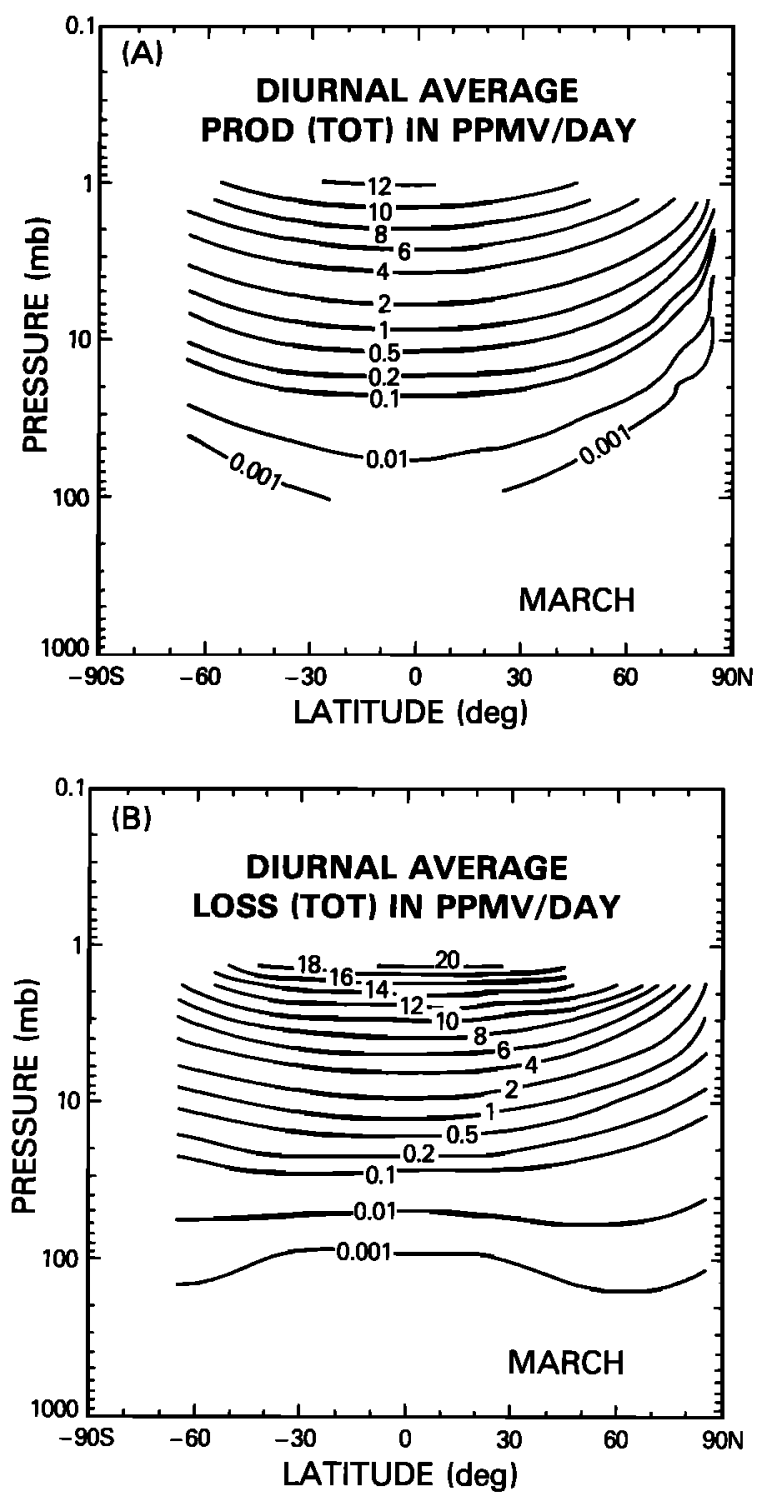

Fig. 7. (a) Total ozone production $P$ in ppmv/d for March. (b) Total ozone loss $L$ in ppmv/d for March.

Finally, the $L\left(\mathrm{Cl}_{x}\right)$ term is represented as

$$
L\left(\mathrm{Cl}_{x}\right)=2 k_{78}[\mathrm{ClO}][\mathrm{O}]
$$

A test of these approximations indicates that the neglected terms are never much more that $1 \%$ of those included at 2 mbar and $5^{\circ} \mathrm{N}$ latitude.

We use the LIMS data (described by Remsberg et al. [1984], Russell et al. [1984a, b], and Gille et al. $[1984 a, b])$ and SAMS data in a monthly and zonally averaged form. The LIMS data consist of four species $\left(\mathrm{O}_{3}, \mathrm{H}_{2} \mathrm{O}, \mathrm{HNO}_{3}\right.$, and $\left.\mathrm{NO}_{2}\right)$ and temperature. Seven months of LIMS data are available, November 1978 through May 1979. We correct the $\mathrm{HNO}_{3}$ LIMS data above 5 mbar by using the expression given by Jackman et al. [1985]. We also use the SAMS $\mathrm{CH}_{4}$ data above $20 \mathrm{mbar}$ which are available for all 12 months of the year. The data are placed into bins of the same size as the two-dimensional model described by Guthrie et al. [1984a]. We use the framework of this two-dimensional model for all calculations, and in most calculations the transport is set to zero. We have included the effects of scattering in all calculations utilizing the two-stream radiative transfer method discussed by Herman
[1979] which is based on the matrix operator method of Plass et al. [1973].

We use a diurnal average method from Turco and Whitten [1978] in which the daytime and nighttime averages of species concentrations are found, and the length of day versus night is considered as a function of latitude and season. As discussed by Turco and Whitten, the use of this method of diurnal averaging will cause less than $10 \%$ error for $\mathrm{OH}, \mathrm{HO}_{2}$, and $\mathrm{O}_{3}$ and less than $15 \%$ error for $\mathrm{NO}_{2}$ up to $47 \mathrm{~km}$ (about 1 mbar). We show in the uncertainty calculation section of this paper that other uncertainties inherent in the calculation are much larger than these.

Since the night to day ratios, which we obtain from the model of Herman and McQuillan [1985] (first described by Herman [1979]), are nearly invariant parameters and the principal variation of the diurnal factors with latitude is the length of day, our results should be quantitatively correct for the low to mid latitude regions and at least qualitatively correct for high latitudes. For the purpose of the present study none of the conclusions will be affected by this approximation.

Under the assumption of photochemical steady state, 15
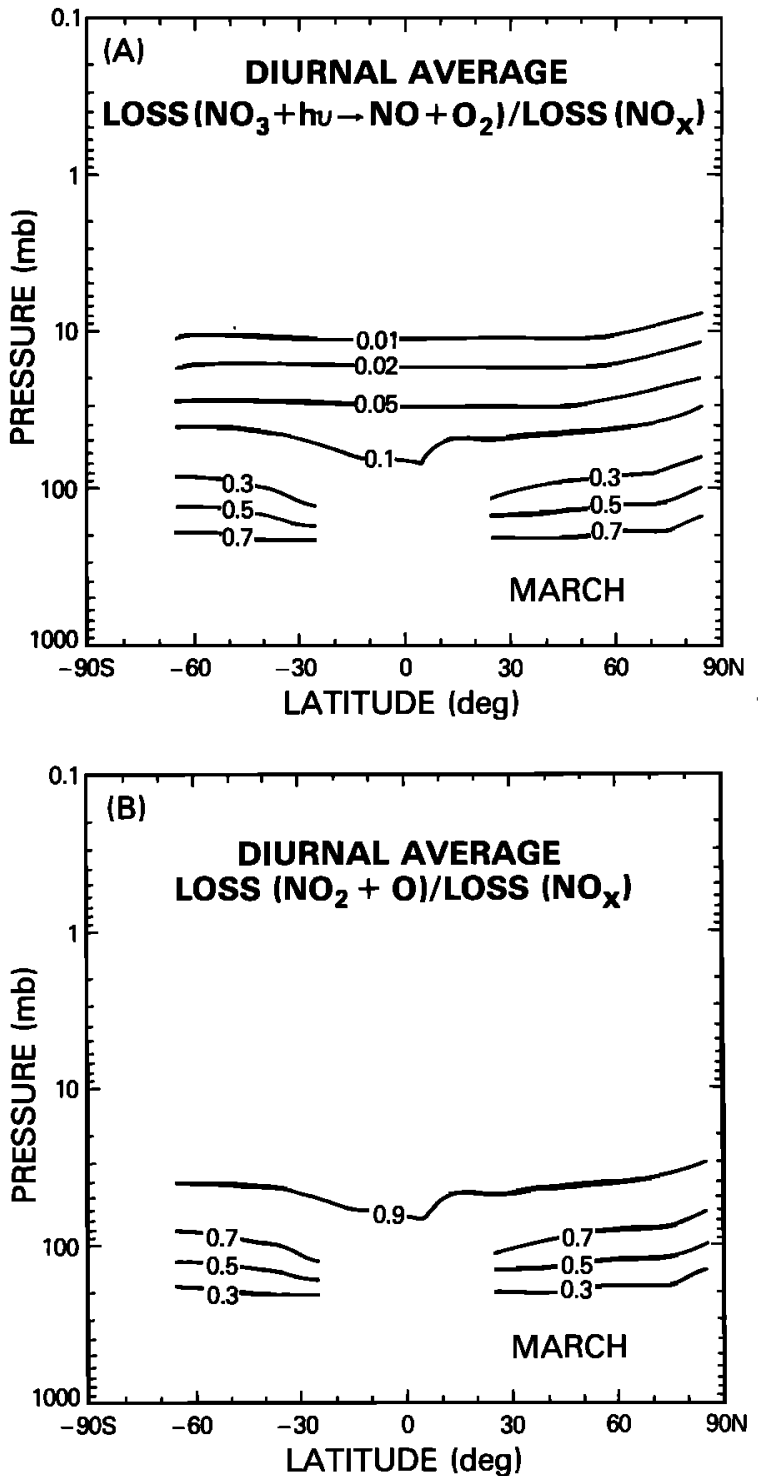

Fig. 8. Fraction of loss in the $\mathrm{NO}_{x}$ family through (a) $\mathrm{NO}_{3}$ photolysis and (b) reaction of $\mathrm{NO}_{2}$ with $\mathrm{O}$. 

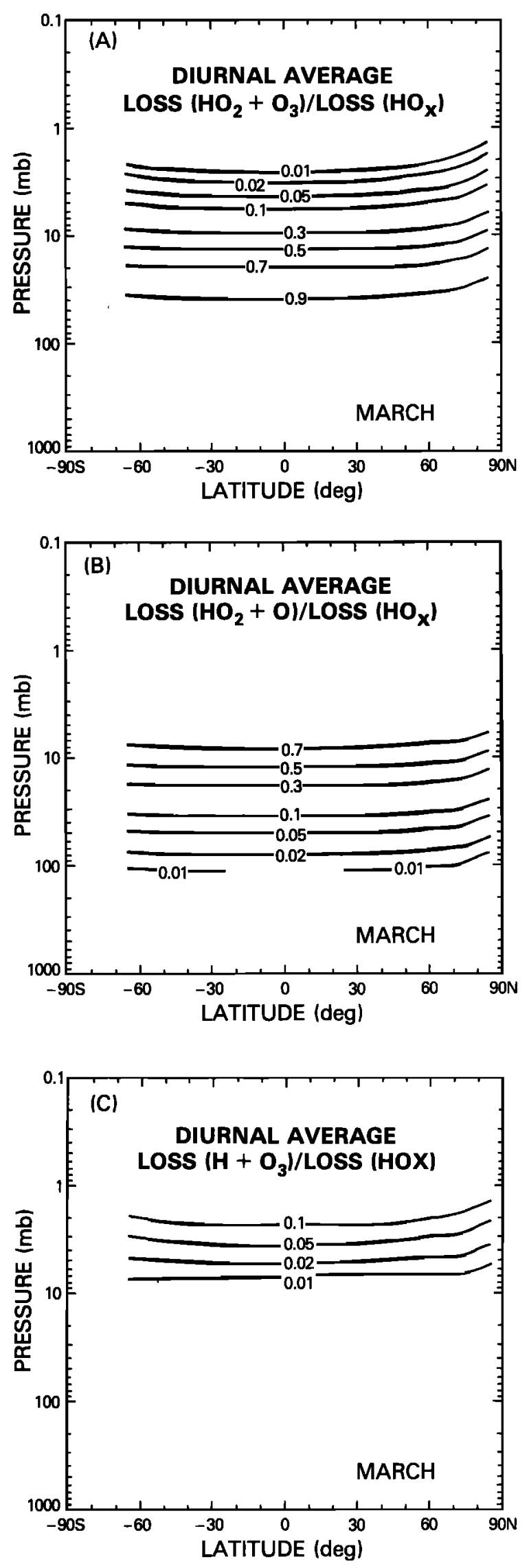

Fig. 9. Fraction of loss in the $\mathrm{HO}_{x}$ family through (a) reaction of $\mathrm{HO}_{2}$ with $\mathrm{O}_{3}$, (b) reaction of $\mathrm{HO}_{2}$ with $\mathrm{O}$, and (c) reaction of $\mathrm{H}$ with $\mathrm{O}_{3}$. species are derived from the LIMS and SAMS data and reactions (R1)-(R70) given in Table 1 . These are $O\left({ }^{3} P\right), O\left({ }^{1} D\right), N$, $\mathrm{NO}, \mathrm{H}, \mathrm{OH}, \mathrm{HO}_{2}, \mathrm{H}_{2} \mathrm{O}_{2}, \mathrm{NO}_{3}, \mathrm{~N}_{2} \mathrm{O}_{5}, \mathrm{HO}_{2} \mathrm{NO}_{2}, \mathrm{CHO}$, $\mathrm{CH}_{2} \mathrm{O}, \mathrm{CH}_{3} \mathrm{O}_{2}$, and $\mathrm{CH}_{3} \mathrm{OOH}$. Concentrations of $\mathrm{CH}_{4}$ below 20 mbar (which merge fairly smoothly with SAMS data) and $\mathrm{CO}$ and $\mathrm{H}_{2}$ over the entire two-dimensional grid were those obtained by Guthrie et al. [1984b] with their two-dimensional model and are believed to be representative of actual stratospheric distributions. The other species needed in order to compute the $P$ and $L$ is $\mathrm{ClO}$, which is calculated using the two-dimensional model with reactions (R1) $(R 91)$. This is the only calculation in which the transport is necessary, since the atmosphere provides the transport in the other calculations because of the use of satellite measured species. We use the finding by Berg et al. [1980] that $\mathrm{Cl}_{x}$ is $3 \mathrm{ppbv}$ near the stratopause and apply this as a constraint in our model. (At the level of analysis being considered, the shape of the $\mathrm{Cl}_{\boldsymbol{x}}$ profile is more or less independent of which source gas is assumed and also is not very dependent on the details of the transport.) We thus put $\mathrm{Cl}_{x}$ into the model via the source gases $\mathrm{CFCl}_{3}(\mathrm{~F}-11)$ and $\mathrm{CF}_{2} \mathrm{Cl}_{2}(\mathrm{~F}-12)$, where the $\mathrm{F}-11$ and F-12 from year 1980 of the run described by Guthrie et al. [1984a] were multiplied by a factor of 4 to obtain $3 \mathrm{ppbv} \mathrm{Cl}$. We specify $\mathrm{CH}_{4}$ to the SAMS data and $\mathrm{O}_{3}, \mathrm{H}_{2} \mathrm{O}, \mathrm{HNO}_{3}$, and $\mathrm{NO}_{2}$ to the LIMS data in order to get the best representation of the chemistry internal to the $\mathrm{Cl}_{x}$ system.

A daytime ClO profile was derived from our model calculation at $35^{\circ} \mathrm{N}$ and is compared with Menzies [1979], Anderson et al. [1980], Weinstock et al. [1981] and Brune et al. [1985] in Figure 1. Our calculations fall near the higher measurements of Anderson et al. [1980], Weinstock et al. [1981], and Brune et al. [1985] if the July 28, 1976, and the July 14, 1977, measurements are excluded. Our daytime $\mathrm{ClO}$ is approximately twice as large as our diurnal ( 24 hour) average $\mathrm{ClO}$ at $25 \mathrm{~km}$ and approximately $30 \%$ higher at $40 \mathrm{~km}$.

Parrish et al. [1981] and Solomon et al. [1984] present column density measurements of $\mathrm{ClO}$. Our daytime $\mathrm{ClO}$ column density calculations $\left(1.3 \times 10^{14} \mathrm{~cm}^{-2}\right.$ and $1.4 \times 10^{13}$ $\mathrm{cm}^{-2}$ above $30 \mathrm{~km}$ and above $40 \mathrm{~km}$, respectively, at $20^{\circ} \mathrm{N}$ latitude in October; and $1.3 \times 10^{14} \mathrm{~cm}^{-2}$ and $1.7 \times 10^{13}$ $\mathrm{cm}^{-2}$ above $30 \mathrm{~km}$ and above $40 \mathrm{~km}$, respectively, at $20^{\circ} \mathrm{N}$ latitude in December) are higher than the midday peak $\mathrm{ClO}$ column density measurements above $30 \mathrm{~km}$ of Solomon et al. [1984] $\left(7 \times 10^{13} \mathrm{~cm}^{-2}\right.$ and $1.3 \times 10^{13} \mathrm{~cm}^{-2}$ above $30 \mathrm{~km}$ and above $40 \mathrm{~km}$, respectively, at $20^{\circ} \mathrm{N}$ latitude in October; and $7-8 \times 10^{13} \mathrm{~cm}^{-2}$ and $2.0 \times 10^{13} \mathrm{~cm}^{-2}$ above $30 \mathrm{~km}$ and above $40 \mathrm{~km}$, respectively, at $20^{\circ} \mathrm{N}$ latitude in December). This finding is consistent with other model results given in Solomon et al. [1984]. In a related model study Ko and Sze [1984] showed that the agreement between the Solomon et al. [1984] observed intensities of the $\mathrm{ClO}$ emission and their onedimensional model predicted intensities is good, particularly in terms of the night to day ratios. This indicates that use of a diurnal average model is sufficient to study $\mathrm{ClO}$ behavior as a function of latitude.

A column $\mathrm{HCl}$ can also be computed. We find that our values are $20-40 \%$ higher than the recent measurements of Mankin and Coffey [1983] but are close to or lower than the measurements of Girard et al. [1982].

Results given above suggest that a total $\mathrm{Cl}_{x}$ of 3 ppbv in the stratosphere may be slightly high. Unfortunately, the various measurements of $\mathrm{ClO}, \mathrm{HCl}$, and total $\mathrm{Cl}_{x}$ are not all consistent with one another. We complete most of our production and loss computations with a total $\mathrm{Cl}_{x}$ of 3 ppbv but also 

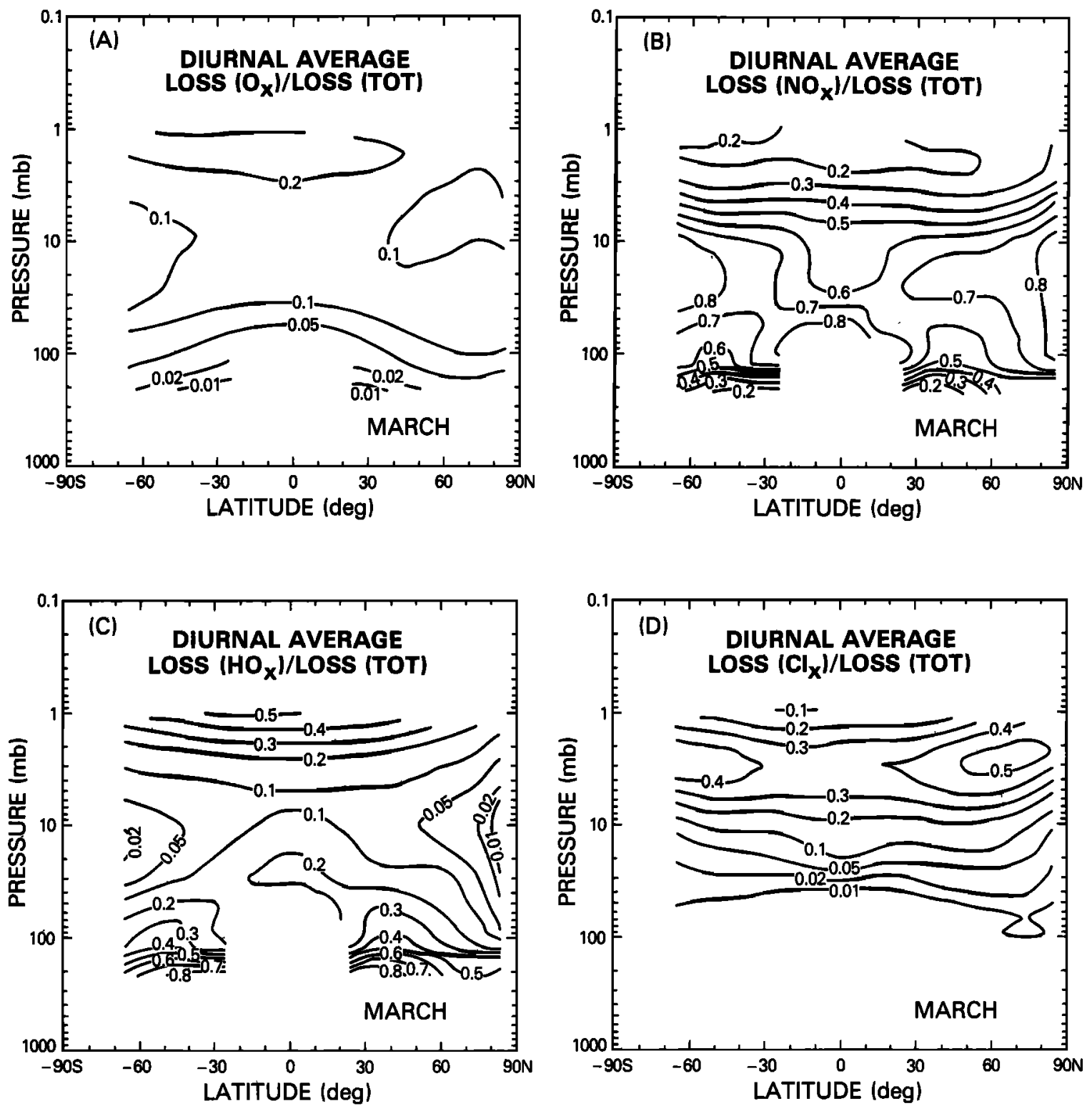

Fig. 10. Fraction of total loss due to the $(a) \mathrm{O}_{x}$ family, (b) $\mathrm{NO}_{x}$ family, (c) $\mathrm{HO}_{x}$ family, and (d) $\mathrm{Cl}_{x}$ family.

indicate the implications of using a total $\mathrm{Cl}_{x}$ of $2 \mathrm{ppbv}$ in these calculations.

\section{Comparison of the Production and LOSS TERMS FOR OZONE}

Using expressions (1) $(6)$ with the $\mathrm{ClO}$ computed as described in the last section, $\mathrm{O}_{3}, \mathrm{H}_{2} \mathrm{O}, \mathrm{HNO}_{3}$, and $\mathrm{NO}_{2}$ from LIMS data, $\mathrm{CH}_{4}$ from SAMS data, $\mathrm{CO}$ and $\mathrm{H}_{2}$ from previous model results, and other species calculated through the use of these assumed species, we can compute the instantaneous production and loss terms for ozone. In this calculation the twodimensional model chemistry is used in the diurnal average mode with the atmosphere providing the transport through the use of its measured constituents. The species densities or mixing ratios are given in Figures 2-6 for $\mathrm{O}_{3}, \mathrm{O}, \mathrm{NO}_{2}, \mathrm{HO}_{2}$, and $\mathrm{ClO}$ for the month of March. The $\mathrm{O}_{3}$ has a peak in mixing ratio near $10 \mathrm{mb}$ at the equator. The $\mathrm{O}$ is related to $\mathrm{O}_{3}$ very closely, and in the lower stratosphere the shape of the $O$ and $\mathrm{O}_{3}$ contours are very similar. $\mathrm{NO}_{2}$ has a peak in mixing ratio near 4 mbar and does not have a strong latitudinal gradient. The $\mathrm{HO}_{2}$ has a fairly uniform distribution over the middle of the stratosphere near low latitudes but has a sharp gradient at the mid- to high latitudes. The $\mathrm{ClO}$ mixing ratio two-dimensional grid is shaped differently from all the others because it reaches its maximum values in the upper stratosphere at the high latitudes, a pattern also computed by Solomon and Garcia [1984].

The production and loss of ozone in $\mathrm{ppmv} / \mathrm{d}$ is given in Figures $7 a$ and $7 b$, respectively. The production and loss of ozone increase from the bottom to the top of the stratosphere.

How do the individual terms in each loss expression compare with one another? The $L\left(\mathrm{NO}_{x}\right)$ and $L\left(\mathrm{HO}_{x}\right)$ expressions are composed of two or more terms. The $L\left(\mathrm{NO}_{x}\right)$ terms are compared in Figures $8 a$ and $8 b$ for the month of March; and the $2 J_{6}\left[\mathrm{NO}_{3}\right]$ term dominates in the lower stratosphere and upper troposphere, while the $2 k_{25}\left[\mathrm{NO}_{2}\right]$ [O] term dominates throughout the rest of the stratosphere.

The three largest $L\left(\mathrm{HO}_{x}\right)$ terms, representing more than $95 \%$ of $L\left(\mathrm{HO}_{x}\right)$, are compared in Figures $9 a, 9 b$, and $9 c$, again for the month of March. The $2 k_{36}\left[\mathrm{HO}_{2}\right]\left[\mathrm{O}_{3}\right]$ term domi- 


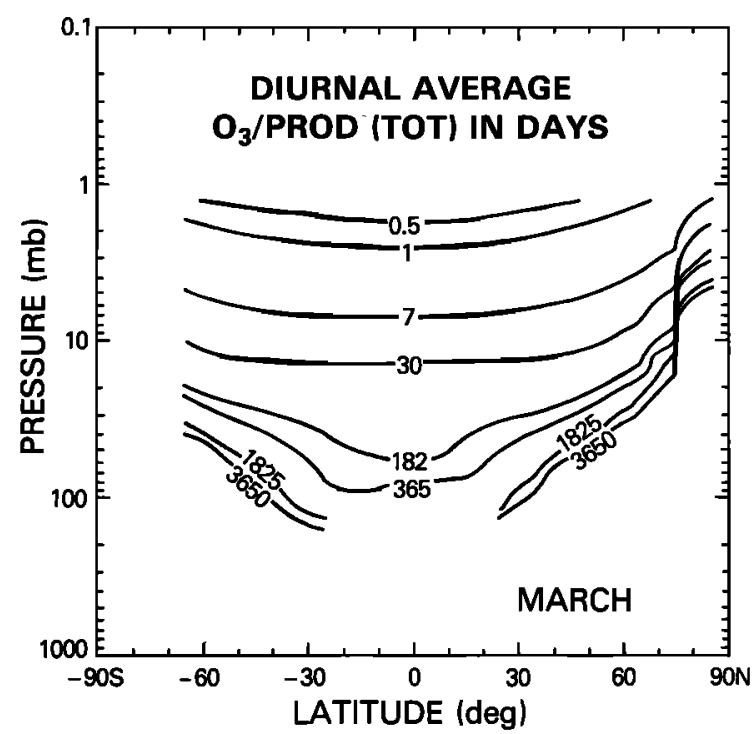

Fig. 11. Replacement time of ozone in days for March.

nates in the lower stratosphere and the $2 k_{38}\left[\mathrm{HO}_{2}\right]$ [O] term dominates in the upper stratosphere. The $2 k_{39}[\mathrm{H}]\left[\mathrm{O}_{3}\right]$ term never dominates but does become larger in the upper stratosphere.

How do the total loss terms from each family compare with each other? In Figures $10 a-10 d$ we compare the fraction of loss due to the $\mathrm{O}_{x}, \mathrm{NO}_{x}, \mathrm{HO}_{x}$, and $\mathrm{Cl}_{x}$ families. The $\mathrm{O}_{x}$ family loss reaches its maximum contribution of slightly greater than $20 \%$ in the upper stratosphere. The $\mathrm{NO}_{x}$ family loss is dominant throughout much of the stratosphere and starts to taper off in value only in the highest and the lowest parts of the stratosphere. In the upper and lower stratosphere the $\mathrm{HO}_{x}$ family loss is important. The $\mathrm{Cl}_{\boldsymbol{x}}$ family loss is important above $10 \mathrm{mbar}$ and for a given pressure level is more important at the higher latitudes.

We compute a replacement time with the method given by Solomon et al. [1980] and represent it as

$$
T=\left[\mathrm{O}_{3}\right] / P
$$

The results of this calculation for March are given in Figure 11. The replacement time varies from less than a day at the top of the stratosphere to several years near the bottom. Regions where $T$ values are less than a week are considered to have "photochemical" control. Recently, Rood and Douglass [1985] and Douglass et al. [1985] have shown that one must be careful in assigning the term "photochemical" to regions of the atmosphere at and above $40^{\circ}$ latitude, where $T$ values are less than a week. They showed that for ozone the dynamical terms are the same size or larger than the chemical terms at and above $40^{\circ}$ latitude during certain times of the year. For this reason our conclusions focus on the photochemical region located in the low latitudes (below $30^{\circ}$ latitude).

From Figure 11 it is apparent that the region near 2 mbar at the low latitudes is photochemically controlled. Ozone is thought to be in photochemical equilibrium in this region, meaning that $P$ should equal $L$. We compute $L / P$ for all 7 months of LIMS data; four representative months are presented in Figure 12. Values of about 1.4-1.6 are found for $L / P$ in the photochemical region. These values imply that photochemical models using LIMS $\mathrm{H}_{2} \mathrm{O}, \mathrm{HNO}_{3}, \mathrm{NO}_{2}$, and temperature and SAMS $\mathrm{CH}_{4}$ will compute lower ozone concentrations than those observed in LIMS data. The results are very similar to those given by Wofsy [1978], Frederick et al. [1978, 1984], Butler [1978], Johnston and Podolske [1978], Solomon et al. [1983], and Crutzen and Schmailzl [1983].

All four family loss processes are important near 2 mbar at the low latitudes (observe in Figure 10). $L\left(\mathrm{NO}_{x}\right.$ ) contributes about $20 \%, L\left(\mathrm{O}_{x}\right)$ and $L\left(\mathrm{HO}_{x}\right)$ each contribute about $25 \%$, and $L\left(\mathrm{Cl}_{x}\right)$ contributes about $30 \%$ of the total loss. As we noted earlier in our discussion of the $\mathrm{ClO}$ two-dimensional distributions (used in computing $L\left(\mathrm{Cl}_{x}\right.$ )), the total $\mathrm{Cl}_{x}$ of 3 ppbv may be slightly high for the stratosphere. If the total $\mathrm{Cl}_{x}$ is reduced to $2 \mathrm{ppbv}$ in the stratosphere, then $L\left(\mathrm{O}_{x}\right)$ and $L\left(\mathrm{HO}_{x}\right)$ each contribute about $28 \%$ and $L\left(\mathrm{NO}_{x}\right)$ and $L\left(\mathrm{Cl}_{x}\right)$ each contribute about $22 \%$ of the total loss near 2 mbar at the low latitudes. With this new $L\left(\mathrm{Cl}_{x}\right)$, values of $1.26-1.44$ are computed for $L / P$ in the photochemical region. An imbalance between $L$ and $P$ still exists, but it is not as pronounced as before.

We now examine the $L / P$ behavior in other regions of the stratosphere, concentrating first on the $L / P$ values for March. The $L$ and the $P$ have differently shaped contours in the lower stratosphere and higher latitudes (see Figures $7 a$ and $7 b$ ). The $P$ depends on the shorter wavelengths $(<242 \mathrm{~nm})$ because of its dependence on the photodissociation of molecular oxygen. The $L$ depends on longer wavelengths ( $<1140 \mathrm{~nm}$ ) because of its dependence on the photodissociation of ozone. Note the large dependence of $L$ on atomic oxygen, $O$. Photons with wavelengths below $242 \mathrm{~nm}$ are absorbed quite efficiently at the very large column densities of $\mathrm{O}_{2}$ and $\mathrm{O}_{3}$, for high latitudes and low altitudes; thus not much ozone production is permitted. Most of the photons between 300 and $1140 \mathrm{~nm}$ are not affected by $\mathrm{O}_{2}$ and $\mathrm{O}_{3}$. These photons lead to the production of $O$ which is the critical ingredient in ozone loss. The sun must be shining for substantial ozone loss to take place, as $\mathbf{O}$ goes away quite rapidly with sunset. Thus when the sun first rises and just before it sets, $L$ will be much greater than $P$.

The steep, generally slanted, contour cliff (observed in Figure 12) in the low to middle stratosphere and above $30^{\circ}$ latitude is the result of the $P$ being reduced. Larger optical depths, resulting from the $\mathrm{O}_{2}$ and $\mathrm{O}_{3}$ column, cause significantly greater absorption of photons with wavelengths less than $242 \mathrm{~nm}$. The production dominates the loss below about 10 mbar between $-30^{\circ}$ and $+30^{\circ}$ latitude in March. The production and loss rates, however, are both virtually insignificant in this region.

The shape of the contour line 1.0 (production = loss) in the 4 months plotted in Figure 12 indicates apparent solar zenith angle control. In November it is asymmetrically aligned bulging toward the southern hemisphere; in January it is fairly symmetric but centered about $15^{\circ} \mathrm{S}$ rather than the equator; in March it is centered over the equator and appears to be bulging slightly toward the northern hemisphere; and in May it is asymmetric bulging toward the northern hemisphere.

\section{UnCertainty Calculation}

In order to assess the significance of the result that $\mathrm{O}_{3}$ production exceeds $\mathrm{O}_{3}$ loss by $40-60 \%$ in the photochemical region, we perform an uncertainty analysis. This analysis uses a modified (to include Cl-containing species) version of the method used by Kaye and Jackman [this issue] (hereafter referred to as $\mathrm{KJ}$ ) to infer daytime concentrations of $\mathrm{HO}_{x}$ and $\mathrm{NO}_{x}$ species from LIMS data. As discussed in some detail by $\mathrm{KJ}$, this method yields multiplicative values for the uncertainties $u_{i}$ in the inferred concentrations of trace species $i$, that is, a species found to have concentration $\left[M_{i}\right]$ with uncer- 

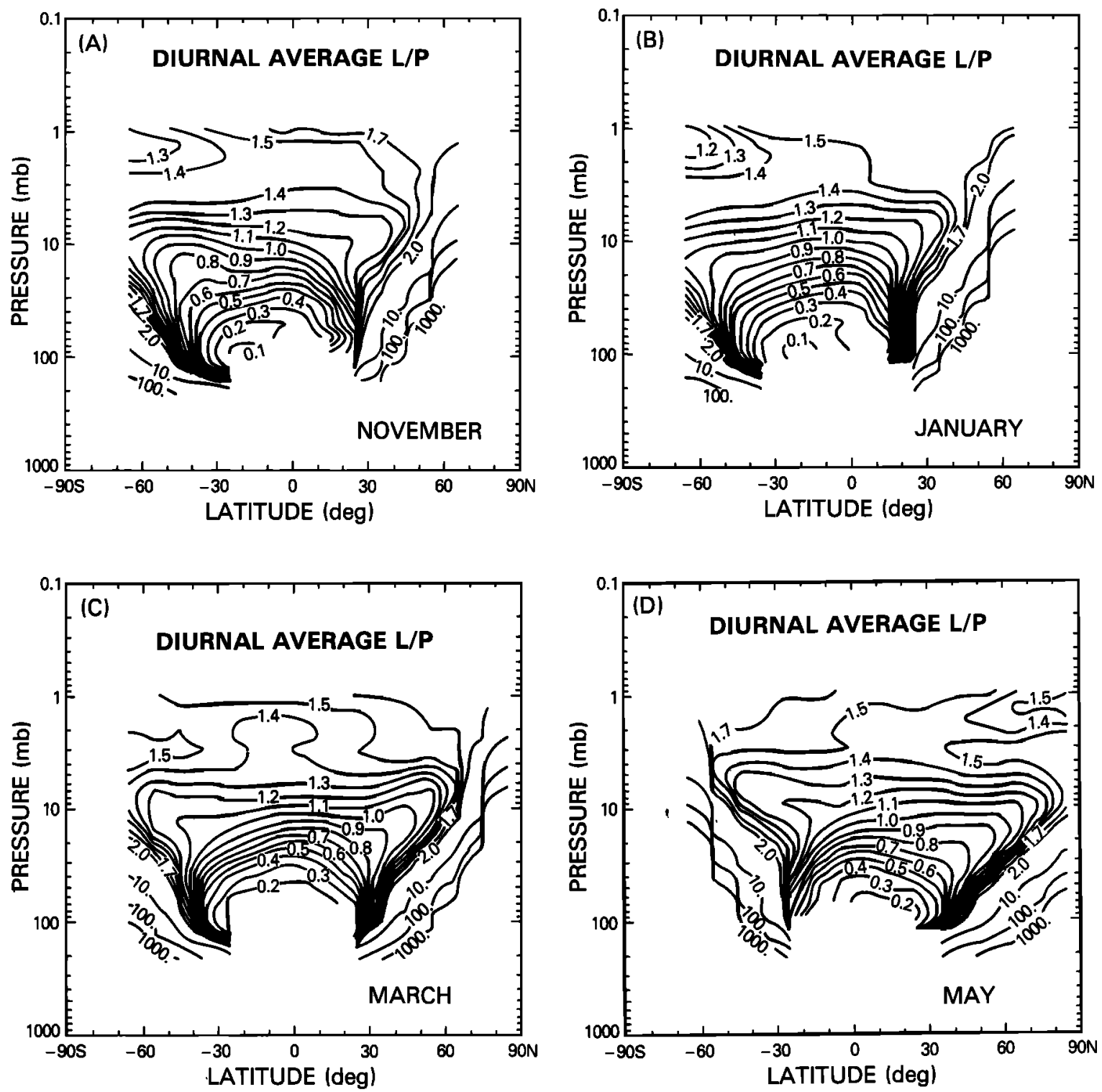

Fig. 12. Ratio of total ozone loss $L$ to total ozone production $P$ for (a) November 1978, (b) January 1979, (c) March 1979, and (d) May 1979.

tainty $u_{i}$ is expected to lie in the range from $\left[M_{i}\right] / u_{i}$ to $u_{i}\left[M_{i}\right]$.

Uncertainties are calculated by the expression given by $\mathbf{K J}$ :

$$
u_{i}=\exp \left[\sum_{j}\left(S_{i j} \ln f_{j}\right)^{2}\right]^{1 / 2}
$$

where $S_{i j}$ is the sensitivity coefficient (logarithmic derivative)

$$
S_{i j}=\partial \ln \left[M_{i}\right] / \partial \ln P_{j}=\frac{P_{j} \partial\left[M_{i}\right]}{\left[M_{i}\right] \partial P_{j}}
$$

where $P_{j}$ is a model input parameter (photolysis rate, reaction rate, concentration) and $f_{J}$ is the uncertainty in parameter $j$. The values and significance are discussed by $\mathrm{KJ}$. We note that reaction rate uncertainties are $1 \sigma$ [DeMore et al., 1983]. Sensitivity coefficients are obtained by analytic differentiation of the algebraic expressions of KJ. The expressions used for inferring trace species concentrations in the enlarged (Clcontaining) version of the model are only slightly different from those of $\mathrm{KJ}$. We list those expressions for Cl-containing species in the appendix.

The uncertainty analysis was performed for the month of March. Results for the uncertainty factor of the $L / P$ ratio as a function of latitude and altitude due to species concentrations, binary and tertiary reaction rates, and photodissociation rates are given in Figures $13 a-13 c$. The total uncertainty factor of the $L / P$ ratio is shown in Figure $13 d$.

Throughout most of the upper stratosphere, this uncertainty factor is close to 1.7. This indicates that the imbalance may well be due to inaccuracies in the included chemistry and species concentrations rather than omitted chemistry.

Uncertainty factor values are near two in the lower stratosphere, where the $L / P$ ratios go to as low as 0.2 . Thus, in this region, where $\mathrm{O}_{3}$ is not expected to be in photochemical equilibrium, input parameter uncertainty cannot be responsible for the imbalance; it must be real.

In Table 2 we consider which of the model input parameters 

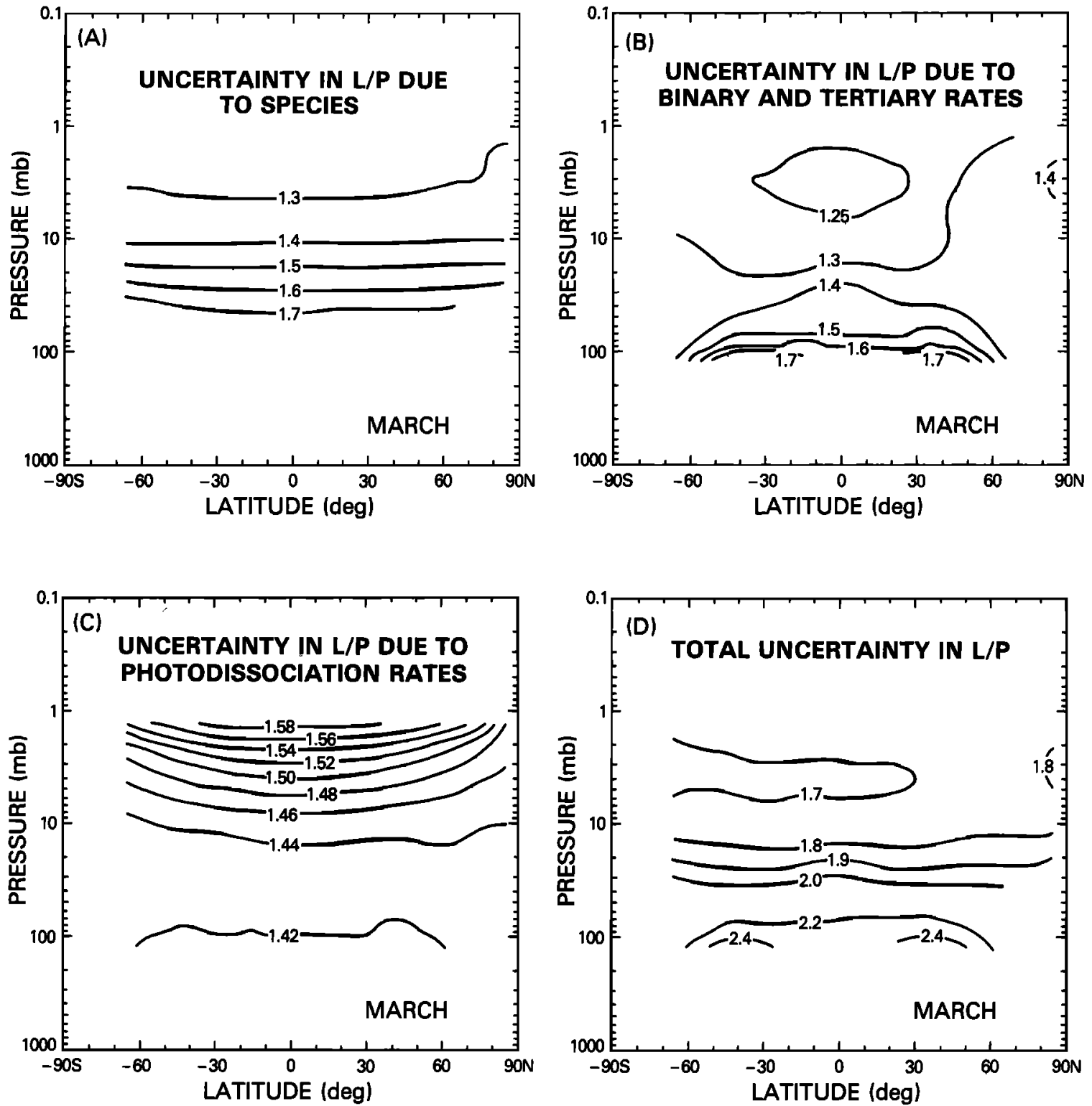

Fig. 13. Uncertainties in the $L / P$ computation due to $(a)$ species, $(b)$ binary and tertiary reaction rates, (c) photodissociation rates, and $(d)$ total of species, binary and tertiary reaction rates, and photodissociation rates.

make the largest contributions to the total uncertainty in $L / P$ at $5^{\circ} \mathrm{N}$ near 2 mbar. The contribution for a given input parameter depends on both the sensitivity coefficient and the input parameter uncertainty. The input parameters with the largest sensitivity coefficients are shown in Table 2 , along with the uncertainties and the product $S_{i j} \ln f_{j}$ which contributes to the sum in (8).

In lower latitudes near $2 \mathrm{mbar}$, the uncertainty in $L / P$ is dominated by three input parameters: the measured $\mathrm{O}_{3}$ concentration, the rate of the photolysis of $\mathrm{O}_{3}$ to $O\left({ }^{1} D\right)$, and the rate of photolysis of $\mathrm{O}_{2}$. These three alone would lead to an uncertainty factor of 1.63 , which is larger than or comparable to the imbalance in the calculated $P$ and $L$. Thus attempts to refine measurements in order to reduce the estimated uncertainty should focus on these terms.

Since photolysis processes (R1) and (R2) are quite important in assessing the total uncertainty in our $L / P$ values, it is necessary to consider the uncertainty that may be added by solar flux uncertainties which are not included in our uncertainty analysis. Error bars are estimated to be $\pm 20 \%$ near $175 \mathrm{~nm}$, $\pm 15 \%$ by $200 \mathrm{~nm}$, and $\pm 10 \%$ by $300 \mathrm{~nm}$ [see World Meteorological Organization, 1982, Appendix B]. Since the solar flux uncertainties are a function of wavelength it would be difficult to include their error bars in our uncertainty analysis. These error bars are substantially less than the quoted uncertainties of a factor of 1.4 in the photodissociation cross sections for (R1) and (R2) (see Table 2) and would not contribute greatly to the uncertainty factor in the $L / P$ ratio anyway. Thus, for the purposes of this uncertainty calculation, the solar flux uncertainties can be neglected.

The large contribution of $\mathrm{O}_{3},(\mathrm{R} 1)$, and (R2) to the total uncertainty is due to the large sensitivity coefficients and large input parameter uncertainty factors, especially for the photolysis processes (R1) and (R2). The uncertainty factor of 1.4 for both of these processes is among the larger uncertainty values. These three input parameters and the rate of the $\mathrm{O}_{3}$ formation reaction (R20) are the only ones with appreciable $(>|0.3|)$ sensitivity coefficients.

The large sensitivity coefficients for these four input parameters may be simply understood by considering the aspects of 
TABLE 2. Input Parameters Making Largest Contribution to Total Uncertainty in $L / P\left(5^{\circ} \mathrm{N}, 2\right.$ mbar $)$

\begin{tabular}{lrlr}
\hline \multicolumn{1}{c}{ Input Parameter } & \multicolumn{1}{c}{$S_{L / P, J}$} & \multicolumn{1}{c}{$f_{J}$} & \multicolumn{1}{c}{$S_{L / P_{J} J} \ln f_{j}$} \\
\hline$J_{1}\left(\mathrm{O}_{2} \rightarrow 2 \mathrm{O}\right)$ & -0.991 & 1.4 & -0.336 \\
$\left.J_{2}\left(\mathrm{O}_{3} \rightarrow \mathrm{O}^{1} \mathrm{D}\right)+\mathrm{O}_{2}\right)$ & 0.800 & 1.4 & 0.269 \\
$\mathrm{O}_{3}\left(\mathrm{OH}+\mathrm{HO}_{2} \rightarrow \mathrm{H}_{2} \mathrm{O}+\mathrm{O}_{2}\right)$ & -0.207 & 1.16 & 0.228 \\
$k_{42}\left(\mathrm{OH}+\mathrm{O}_{2}+\mathrm{M} \rightarrow \mathrm{O}_{3}+\mathrm{M}\right)$ & -0.801 & 1.14 & -0.135 \\
$k_{20}\left(\mathrm{O}+\mathrm{O}_{2}\right.$ & 0.250 & 1.51 & 0.106 \\
$k_{36}\left(\mathrm{O}+\mathrm{HO}_{2} \rightarrow \mathrm{OH}+\mathrm{O}_{2}\right)$ & 0.262 & 1.26 & 0.061 \\
$k_{19}\left(\mathrm{O}+\mathrm{O}_{3} \rightarrow 2 \mathrm{O}_{2}\right)$ & 0.224 & 1.24 & 0.048 \\
$\mathrm{H}_{2} \mathrm{O}$ & 0.186 & 1.25 & 0.041 \\
$k_{79}\left(\mathrm{OH}+\mathrm{HCl} \rightarrow \mathrm{H}_{2} \mathrm{O}+\mathrm{Cl}\right)$ & 0.214 & 1.20 & 0.039 \\
$\mathrm{Cl}$ & 0.177 & 1.25 & 0.039 \\
$k_{23}\left(\mathrm{O}\left({ }^{1} \mathrm{D}\right)+\mathrm{H}_{2} \mathrm{O} \rightarrow 2 \mathrm{OH}\right)$ & 0.199 & 1.19 & 0.035 \\
$k_{77}\left(\mathrm{Cl}+\mathrm{O}_{3} \rightarrow \mathrm{ClO}+\mathrm{O}_{2}\right)$ & 0.177 & 1.20 & 0.032 \\
$\mathrm{NO}_{2}$ & 0.188 & 1.16 & 0.028 \\
$k_{25}\left(\mathrm{O}+\mathrm{NO}_{2} \rightarrow \mathrm{NO}+\mathrm{O}_{2}\right)$ & 0.187 & 1.15 & 0.026 \\
$J_{3}\left(\mathrm{O}_{3} \rightarrow \mathrm{O}+\mathrm{O}_{2}\right)$ & & & \\
\hline
\end{tabular}

the chemistry responsible for $\mathrm{O}_{3}$ loss and production and by recognizing that the sensitivity coefficient corresponds to the power law dependence of the output parameter $\left[M_{i}\right]$ on the input parameter $P_{j}$

$$
\left[M_{i}\right] \propto P_{j}^{S_{i j}}
$$

Thus a sensitivity coefficient of one implies linear dependence, one of two implies quadratic dependence, etc.

The sensitivity coeflicient of -0.99 for $J_{1}$ occurs because odd oxygen production is proportional to $J_{1}$ if one neglects radiative feedback effects, while odd oxygen loss is nearly independent of it. Since the ratio $L / P$ is inversely proportional to $P$, it will also be essentially inversely proportional to $J_{1}$.

The approximate $3 / 2$ power dependence of $L / P$ on $\mathrm{O}_{3}$ is due to a dependence of the loss rate $L$ on $\mathrm{O}_{3}$; neglecting radiative feedback effects $P$ is independent of $\mathrm{O}_{3}$. If odd oxygen loss were due entirely to $O_{x}$ (by (R19)), the dependence of $L$ on $\mathrm{O}_{3}$ would be nearly quadratic, since the concentration of atomic oxygen is nearly proportional to that of $\mathrm{O}_{3}$. If odd oxygen loss were only due to the $\mathrm{NO}_{x}$ term, its dependence on $\mathrm{O}_{3}$ would be linear, as the concentration of $\mathrm{NO}_{2}$ is fixed by LIMS and $\mathrm{O}$ is proportional to $\mathrm{O}_{3}$. If odd oxygen loss were due entirely to the $\mathrm{HO}_{x}$ terms, there would be approximately a 3/2 power dependence on $\mathrm{O}_{3}$. This comes from the fact that $\mathrm{HO}_{x}$ loss in the upper stratosphere is dominated by (R36) $\left(\mathrm{O}+\mathrm{HO}_{2} \rightarrow \mathrm{OH}+\mathrm{O}_{2}\right)$, and $\mathrm{HO}_{2}$ scales approximately as the square root of $\mathrm{O}_{3}$ there $(\mathrm{KJ})$. If $\mathrm{Cl}_{x}$ loss dominated odd oxygen loss, it would vary with $\mathrm{O}_{3}$ as approximately the 1.6 power, as $\mathrm{ClO}$ is proportional to $\mathrm{O}_{3}$ to the 0.6 power. Thus odd oxygen loss is due to a combination of four terms, each varying with $\mathrm{O}_{3}$ with a power law dependence between linear and quadratic, so the overall dependence must also be between linear and quadratic.

The approximate linear dependence of $L / P$ on the rate of $\mathrm{O}_{3}$ photolysis (R2) and the nearly inverse dependence on (R20) are again due to the loss term only, as $P$ is independent of these rates (neglecting radiative feedback effects for the photolysis rates). Since essentially all odd oxygen loss processes in the upper stratosphere involve atomic oxygen, the odd oxygen loss rate will be proportional to the rate of processes producing (mainly (R2) at 2 mbar) and removing (mainly, (R20)) atomic oxygen. The deviation of the sensitivity coefficient of $L / P$ with respect to (R20) from -1 is due to the fact that atomic oxygen plays an important role in partitioning of odd hydrogen and odd chlorine species among their respective molecules.

\section{Discussion}

The $L / P$ values show a systematic behavior at low latitudes of increasing with altitude, although near $30^{\circ} \mathrm{N}$ at equinox (March) there is a tendency for the $L=P$ line to be nearly vertical up to 10 mbar even in the dynamical region, which implies that a photochemical calculation may give a correct ozone even though the strict conditions for photochemical equilibrium are not met. The systematic behavior of $L / P$ increasing with altitude suggests that a problem may exist in our calculation of $P$, in spite of the fact that the $L / P$ values are within their uncertainty factors of being equal to 1.0 in the upper stratosphere. This implies that perhaps we are underestimating the photodissociation rate of molecular oxygen; i.e., the photoabsorption cross section may be underestimated for molecular oxygen in the Schumann-Runge or Herzberg continuum. A similar conclusion was given by Solomon et al. [1983] who compared mesospheric ozone from Solar Mesosphere Explorer (SME) measurements with model calculations. Another indication of a problem in the photochemistry near the stratopause was given in the recent paper of Jackman and McPeters [1985], who analyzed differences between theoretical model predictions and measurements of ozone depletions resulting from solar proton events. Jackman and McPeters noted that the ozone depletion observed by satellites was substantially larger than that predicted between 1 and 0.3 mbar.

It is evident from the discussion of uncertainties in the previous section that by virtue of their large uncertainties the photolysis processes (R1) and (R2) are the most likely ones to contribute to the uncertainty in $L / P$. The fact that these processes, along with (R20) and $\mathrm{O}_{3}$, are the only input parameters for which the sensitivity coefficient of $L / P$ is greater than 0.3 means that it is highly unlikely that uncertainties in any or all of the other model input parameters could be responsible for the deviation of $L / P$ as far from unity as has been inferred. Relative insensitivity of $L / P$ to most of the other chemical reaction rates, photolysis rates, and concentrations is quite reasonable, given the roughly equal distribution of odd oxygen loss among oxygen, nitrogen, hydrogen, and chlorine terms (see Figure 10 at 2 mbar). Thus even relatively large changes in quantities such as the reaction rates governing the $\mathrm{OH}-\mathrm{HO}_{2}$ partitioning, which might have a major effect on the hydrogen term, would have only a minor effect on the total odd oxygen loss.

Implicit in our calculations and the study of uncertainties is the assumption that our model accurately represents the chemistry of odd oxygen in the stratosphere. Given the systematic excess of odd oxygen loss over production throughout the upper stratosphere, one should critically assess the model to be sure that no odd oxygen production has been neglected.

First, let us consider uncertainties in our only odd oxygen production term, the molecular oxygen absorption cross sections. Most recent papers on molecular oxygen absorption cross sections [see Frederick and Mentall, 1982; Herman and Mentall, 1982; Anderson and Hall, 1983; Cheung et al., 1984; Johnston et al., 1984] indicate that the lower cross-section values, similar to those used in our calculations, are preferred. One recent paper on molecular oxygen absorption cross sections [Pirre et al., 1984], however, indicates that much higher cross sections are suggested. A review of the $\mathrm{O}_{2}$ cross sections 


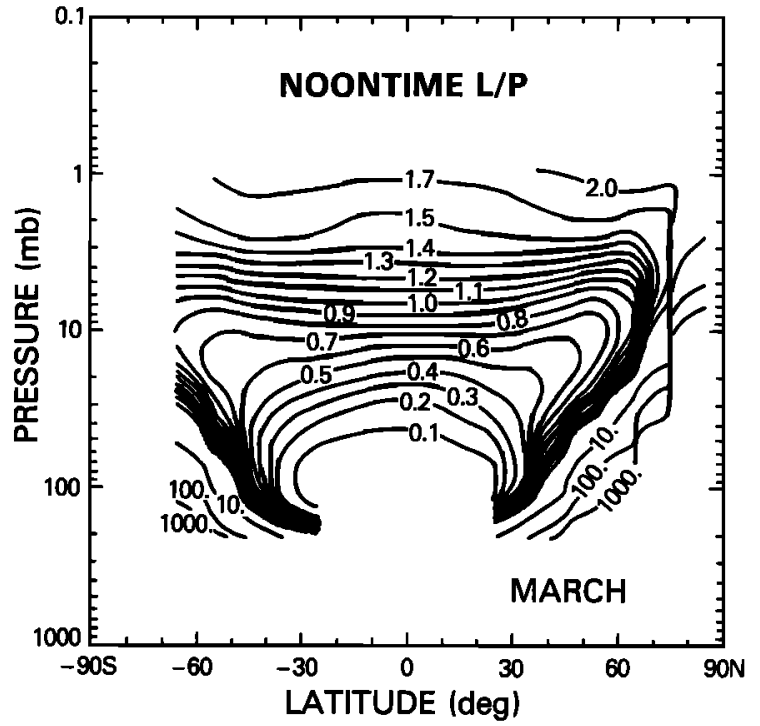

Fig. 14. Ratio of total ozone loss $L$ to total ozone production $P$ for March 1979 from an instantaneous noontime computation.

by a study group [Frederick et al., 1983] recommended the lower cross section values; thus the $\mathrm{O}_{2}$ cross sections used in this study are probably reasonable.

Second, there may exist an additional odd oxygen source which we have neglected. Several additional potential sources have been discussed in the literature. Their contribution for all altitudes, latitudes, and seasons has not been quantitatively presented, however. While these are not expected to be quantitatively significant, we mention them here for the sake of completeness and to help emphasize that in the presence of systematic disagreements between the calculated odd oxygen production and loss rates (or alternatively, the observed and predicted ozone distributions), it is important to refine calculations of possible odd oxygen sources in the upper stratosphere.

An additional source suggested is enhanced oxygen photolysis due to the preferential photolysis of isotopically heavy oxygen $\left({ }^{34} \mathrm{O}_{2}={ }^{16} \mathrm{O}^{18} \mathrm{O}\right)$, originally discussed by Cicerone and McCrumb [1980]. Their original calculations suggested possible enhancement of oxygen at $65 \mathrm{~km}$ by $20-30 \%$ from this mechanism, indicating its possible importance in the mesosphere and upper stratosphere. More recent calculations [Blake et al., 1984] indicate a maximum contribution of some $3 \%$ at $70 \mathrm{~km}$, with a $1 \%$ contribution at $50 \mathrm{~km}$. While this contribution represents a marked enhancement over the $0.4 \%$ contribution to $\mathrm{O}_{2}$ photolysis expected on the basis of the fractional abundance of ${ }^{34} \mathrm{O}_{2}$ relative to the predominant ${ }^{32} \mathrm{O}_{2}$, it is not nearly enough to account for the systematic underestimate of odd oxygen production presented here.

Another source of odd oxygen has been proposed by Frederick and Cicerone [1985] which involves the photolysis of $\mathrm{O}_{2}\left(a^{1} \Delta_{g}\right)$. The magnitude of this source is still not known. However, if we use $7.5 \times 10^{-20} \mathrm{~cm}^{2}$ for the peak value of the cross section, then $L=P$ near $1.5 \mathrm{mbar}$ and low latitudes. This indicates that an improvement in the ozone balance in the upper stratosphere is possible with this suggested odd oxygen source.

It is possible that computing the $L / P$ terms using the diurnal cycle rather than just a diurnal average would give a slightly different result than that obtained here. We compute the instantaneous $L / P$ terms using the daytime set of LIMS data for March 1979 in order to investigate this possibility,

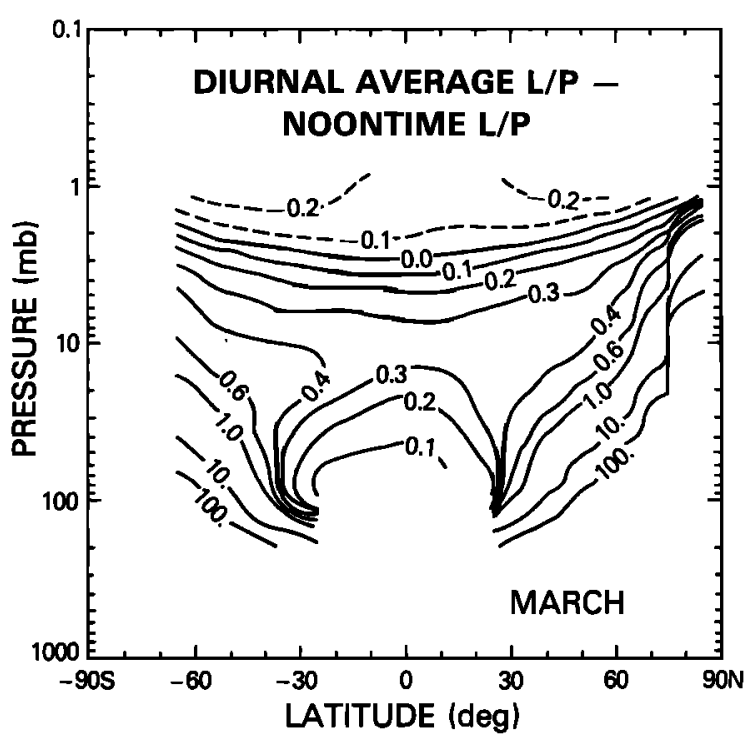

Fig. 15. Difference between $L / P$ from an instantaneous diurnal average computation and $L / P$ from an instantaneous noontime calculation for March 1979.

and we present our results in Figure 14. Since the daytime set of LIMS data were taken at a time close to local noon at most latitudes, we compute the $L / P$ fixing the time at local noon. Differences between the diurnal average and the local noontime $L / P$ distributions are apparent (compare Figures $12 c$ and 14). A two-dimensional difference grid of $L / P$ from the diurnal average calculation and $L / P$ from the noontime calculation is given in Figure 15. Near 2 mbar at the low latitudes where photochemical equilibrium should hold, both the $L / P$ from the diurnal average calculation and the $L / P$ from the noontime calculation are nearly the same, with the $L / P$ from the noontime calculation being slightly larger. We thus conclude that a calculation of the $L / P$ terms using a full diurnal cycle will result in similar conclusions arrived at using a diurnal average approximation.

\section{CONCLUSIONS}

We have calculated the monthly and zonally averaged loss and production rates for ozone using recent Nimbus 7 satellite measurements of stratospheric constituents and accepted reaction and photodissociation rates. We found that ozone has a loss rate that is about $40-60 \%$ higher than the production in the photochemical region. The uncertainties in our calculation were a factor of 1.7. This indicated, therefore, that we could not conclude that the photochemistry was incomplete. Inaccuracies in the assumed reaction and photodissociation rates and stratospheric constituents could be sufficient to cause the $L / P$ discrepancy. The systematic behavior of the $L / P$ twodimensional grid indicated, however, that there could be a problem with the $P$ calculation. The measurements of constituents (especially, $\mathrm{O}_{3}$ ), reaction rates, and photodissociation rates (especially $J_{1}$ and $J_{2}$ ) should be made with greater accuracy in order to better determine areas of weakness in our understanding of the photochemistry of the stratosphere.

Despite some problems with the magnitude of the deduced $P$ versus the deduced $L$ in the photochemical region, an interesting pattern occurs in the $L / P$ contours. Three distinct regions appear in the $L / P$ contour diagrams: (1) the aforementioned photochemical region, (2) a region in the low-latitude lower stratosphere where $L / P$ is significantly less than one and 
time constants are long enough for dynamics to be important, and (3) a region at high latitudes in the lower stratosphere where $L / P$ is significantly more than one because production goes to zero much faster than loss. Since regions 2 and 3 have significantly long chemical time constants, transport of ozone is implied from 2 to 3, i.e., from low and mid-latitudes to high latitudes. The sharp transition between these regions shows clear evidence of solar control during the march of seasons from November through May.

\section{APPENDIX: Algebraic EXPRESSIONS USED IN SENSITIVITY MODEL FOR INFERRING CONCENTRATIONS of Cl-Containing Species}

Concentrations of $\mathrm{HCl}, \mathrm{Cl}, \mathrm{ClO}, \mathrm{HOCl}$, and $\mathrm{ClONO}_{2}$ used in the sensitivity analysis are inferred in an iteration loop using the following expressions:

$$
[\mathrm{HCl}]=\left[\mathrm{Cl}_{x}\right]\left\{1+\mathrm{c}_{1}\left[1+\mathrm{c}_{2}\left(1+\mathrm{c}_{3}+\mathrm{c}_{4}\right)\right]\right\}^{-1}
$$

where

$$
\begin{aligned}
c_{1} & =k_{79}[\mathrm{OH}] / D_{\mathrm{Cl}}=[\mathrm{Cl}] /[\mathrm{HCl}] \\
c_{2} & =k_{77}\left[\mathrm{O}_{3}\right] / D_{\mathrm{clO}}=[\mathrm{ClO}] /[\mathrm{Cl}] \\
c_{3} & =k_{84}\left[\mathrm{HO}_{2}\right] / D_{\mathrm{HOCl}}=[\mathrm{HOCl}] /[\mathrm{ClO}] \\
c_{4} & =k_{91}\left[\mathrm{NO}_{2}\right][\mathrm{M}] / D_{\mathrm{ClONO}_{2}}=[\mathrm{ClONO}] /[\mathrm{ClO}]
\end{aligned}
$$

and

$$
\begin{aligned}
D_{\mathrm{Cl}} & =k_{80}\left[\mathrm{CH}_{4}\right]+k_{82}\left[\mathrm{HO}_{2}\right] \\
D_{\mathrm{ClO}} & =k_{78}[\mathrm{O}]+k_{88}[\mathrm{NO}]+k_{91}\left[\mathrm{NO}_{2}\right][\mathrm{M}] \\
D_{\mathrm{HOCl}} & =J_{74}+k_{85}[\mathrm{OH}] \\
D_{\mathrm{ClONO}_{2}} & =J_{76}+k_{87}[\mathrm{O}]
\end{aligned}
$$

Acknowledgments. We thank Paul D. Guthrie and Marvin A. Geller (both of NASA Goddard Space Flight Center) for many useful discussions and encouragement and both Roberta A. Duffy and Michele D. James (NASA Goddard Space Flight Center) for their careful typing of the manuscript. Contribution 28 of the Stratospheric General Circulation with Chemistry Modeling Project at NASA Goddard Space Flight Center.

\section{REFERENCES}

Anderson, G. P., and L. A. Hall, Attenuation of solar irradiance in the stratosphere: Spectrometer measurements between 191 and 207 nm, J. Geophys. Res., 88, 6801-6806, 1983.

Anderson, J. G., H. J. Grassl, R. E. Shetter, and J. J. Margitan, Stratospheric free chlorine measured by balloon-borne in situ resonance fluorescence, J. Geophys. Res., 85, 2869-2887, 1980.

Berg, W. W., P. J. Crutzen, F. E. Grahek, S. N. Gitlin, and W. A. Sedlacek, First measurements of total chlorine and bromine in the lower stratosphere, Geophys. Res. Lett., 7, 937-940, 1980.

Blake, A. J., S. T. Gibson, and D. G. McCoy, Photodissociation of ${ }^{16} \mathrm{O}^{18} \mathrm{O}$ in the atmosphere, J. Geophys. Res., 89, 7277-7284, 1984.

Brune, W. H., E. M. Weinstock, M. J. Schwab, R. M. Stimpfle, and J. G. Anderson, Stratospheric ClO: In situ detection with a new approach, Geophys. Res. Lett., 12, 441-444, 1985.

Butler, D. M., The uncertainty in ozone calculations by a stratospheric photochemistry model, Geophys. Res. Lett., 5, 769-772, 1978.

Cheung, A. S.-C., K. Yoshino, W. H. Parkinson, and D. E. Freeman, Herzberg continuum cross section of oxygen in the wavelength region $193.5-204.0 \mathrm{~nm}$ : New laboratory measurements and stratospheric implications, Geophys. Res. Lett., 11, 580-582, 1984.

Cicerone, R. J., and J. L. McCrumb, Photodissociation of isotopically heavy $\mathrm{O}_{2}$ as a source of atmospheric $\mathrm{O}_{3}$, Geophys. Res. Lett., 7, 251-254, 1980.

Crutzen, P. J., The influence of nitrogen oxides on the atmospheric ozone content, Q.J.R. Meteorol. Soc., 96, 320-325, 1970.
Crutzen, P. J., A review of upper atmospheric chemistry, Can. J. Chem., 52, 1569-1581, 1974.

Crutzen, P. J., and U. Schmailzl, Chemical budgets of the stratosphere, Planet. Space Sci., 31, 1009-1032, 1983.

DeMore, W. B., M. J. Molina, R. T. Watson, D. M. Golden, R. F. Hampson, M. J. Kurylo, C. J. Howard, and A. R. Ravishankara, Chemical kinetics and photochemical data for use in stratospheric modeling, JPL Publ. 83-62, 1983.

Douglass, A. R., R. B. Rood, and R. S. Stolarski, Interpretation of ozone temperature correlations, 2 , Analysis of SBUV ozone data, $J$. Geophys. Res., 90, 10693-10708, 1985.

Frederick, J. E., and R. J. Cicerone, Dissociation of metastable $\mathrm{O}_{2}$ as a potential source of atmospheric odd oxygen, J. Geophys. Res., 90, 10733-10738, 1985.

Frederick, J. E., and J. E. Mentall, Solar irradiance in the stratosphere: Implications for the Herzberg continuum absorption of $\mathrm{O}_{2}$, Geophys. Res. Lett., 9, 461-464, 1982.

Frederick, J. E., B. W. Guenther, P. B. Hays, and D. F. Heath, Ozone profiles and chemical loss rates in the tropical stratosphere deduced from backscatter ultraviolet measurements, J. Geophys. Res., 83, 953-958, 1978.

Frederick, J. E., A. J. Blake, D. E. Freeman, R. W. Nicholls, T. Ogawa, and P. C. Simon, Molecular absorption processes related to the penetration of ultraviolet solar radiation into the middle atmosphere, in Middle Atmosphere Program, Handbook for MAP, vol. 8, edited by C. F. Sechrist, Jr., pp. 53-74, Scientific Committee on Solar Terrestrial Physics, Urbana, Ill., 1983.

Frederick, J. E., G. N. Serafino, and A. R. Douglass, An analysis of the annual cycle in upper stratospheric ozone, J. Geophys. Res., 89, 9547-9555, 1984.

Gille, J. C., and J. M. Russell III, The limb infrared monitor of the stratosphere: Experiment description, performance, and results, $J$. Geophys. Res., 89, 5125-5140, 1984.

Gille, J. C., J. M. Russell III, P. L. Bailey, E. E. Remsberg, L. L. Gordley, W. F. J. Evans, H. Fischer, B. W. Gandrud, A. Girard, J. E. Harries, and S. A. Beck, Accuracy and precision of the nitric acid concentrations determined by the limb infrared monitor of the stratosphere experiment on Nimbus $7, J$. Geophys. Res., 89, 5179$5190,1984 a$.

Gille, J. C., J. M. Russell, P. L. Bailey, L. L. Gordley, E. E. Remsberg, J. H. Lienesch, W. G. Planet, F. B. House, L. V. Lyjak, and S. A. Beck, Validation of temperature retrievals obtained by the limb infrared monitor of the stratosphere (LIMS) experiment on Nimbus 7, J. Geophys. Res., 89, 5147-5160, 1984b.

Girard, A., L. Gramont, N. Louisnard, S. LeBoiteau, and G. Fergnat, Latitudinal variation of $\mathrm{HNO}_{3}, \mathrm{HCl}$, and $\mathrm{HF}$ vertical column density above $11.5 \mathrm{~km}$, Geophys. Res. Lett., 9, 135-138, 1982.

Guthrie, P. D., C. H. Jackman, J. R. Herman, and C. J. McQuillan, A diabatic circulation experiment in a two-dimensional photochemical model, J. Geophys. Res., 89, 9589-9602, 1984a.

Guthrie, P. D., C. H. Jackman, and A. M. Thompson, Methane and carbon monoxide: Budgets and seasonal behavior in a 2-D model simulation, Eos Trans. $A G U, 65,834,1984 b$.

Herman, J. R., The response of stratospheric constituents to a solar eclipse, sunrise, and sunset, J. Geophys. Res., 84, 3701-3710, 1979.

Herman, J. R., and C. J. McQuillan, Atmospheric chlorine and stratospheric ozone: Nonlinearities and trend detection, J. Geophys. Res., $90,5721-5732,1985$

Herman, J. R., and J. E. Mentall, $\mathrm{O}_{2}$ absorption cross sections (187$225 \mathrm{~nm}$ ) from stratospheric solar flux measurements, J. Geophys. Res., 87, 8967-8975, 1982.

Hunt, B. G., Photochemistry of ozone in a moist atmosphere, $J$. Geophys. Res., 71, 1385-1398, 1966.

Jackman, C. H., and R. D. McPeters, The response of ozone to solar proton events during solar cycle 21: A theoretical interpretation, $J$. Geophys. Res., 90, 7955-7966, 1985.

Jackman, C. H., J. A. Kaye, and P. D. Guthrie, LIMS $\mathrm{HNO}_{3}$ data above 5 mbar: Corrections based on simultaneous observations of other species, J. Geophys. Res., 90, 7923-7930, 1985.

Johnston, H. S., and J. Podolske, Interpretations of stratospheric photochemistry, Rev. Geophys., 16, 491-519, 1978.

Johnston, H., and G. Whitten, Instantaneous photochemical rates in the global stratosphere, Pure Appl. Geophys. 106-108, 1468-1489, 1973.

Johnston, H. S., M. Paige, and F. Yao, Oxygen absorption cross sections in the Herzberg continuum and between 206 and $327 \mathrm{~K}, J$. Geophys. Res., 89, 11661-11665, 1984.

Jones, R. L., and J. A. Pyle, Observations of $\mathrm{CH}_{4}$ and $\mathrm{N}_{2} \mathrm{O}$ by the 
Nimbus 7 SAMS: A comparison with in situ data and twodimensional numerical model calculations, J. Geophys. Res., 89, 5263-5279, 1984

Kaye, J. A., and C. H. Jackman, Concentrations and uncertainties of stratospheric trace species inferred from limb infrared monitor of the stratosphere data, 1, Methodology and application to $\mathrm{OH}$ and HO, J. Geophys. Res., this issue.

Ko, M. K. W., and N. D. Sze, Diurnal variation of ClO: Implications for the stratospheric chemistries of $\mathrm{ClONO}_{2}, \mathrm{HOCl}$, and $\mathrm{HCl}, J$. Geophys. Res., 89, 11619-11632, 1984.

Mankin, W. G., and M. T. Coffey, Latitudinal distributions and temporal changes of stratospheric $\mathrm{HCl}$ and $\mathrm{HF}, J$. Geophys. Res., 88 , 10776-10784, 1983.

Menzies, R. T., Remote measurement of $\mathrm{ClO}$ in the stratosphere, Geophys. Res. Lett., 6, 151-154, 1979.

Molina, M. J., and F. S. Rowland, Stratospheric sink for chlorofluoromethanes: Chlorine atom-catalysed destruction of ozone, Nature, 249, 810-812, 1974.

Mount, G. H., and G. J. Rottman, The solar spectral irradiance 1200 3184 \& near solar maximum: July 15, 1980, J. Geophys. Res., 86, 9193-9198, 1981.

Parrish, A., R. L. de Zafra, P. M. Solomon, J. W. Barrett, and E. R. Carlson, Chlorine oxide in the stratospheric ozone layer: Groundbased detection and measurement, Science, 211, 1158-1161, 1981.

Pirre, M., P. Rigaud, and D. Huguenin, New in situ measurements of the absorption cross sections of $\mathrm{O}_{2}$ in the Herzberg continuum, Geophys. Res. Lett., 11, 1199-1202, 1984.

Plass, G. N., G. W. Kattawar, and F. E. Catchings, Matrix operator theory of radiative transfer, 1, Rayleigh scattering, Appl. Opt., 12, 314-329, 1973.

Remsberg, E. E., J. M. Russell III, J. C. Gille, L. L. Gordley, P. L. Bailey, W. G. Planet, and J. E. Harries, The validation of Nimbus 7 LIMS measurements of ozone, J. Geophys. Res., 89, 5161-5178, 1984.

Rood, R. B., and A. R. Douglass, Interpretation of ozone temperature correlations, 1, Theory, J. Geophys. Res., 90, 5733-5743, 1985.

Russell, J. M., III, J. C. Gille, E. E. Remsberg, L. L. Gordley, P. L. Bailey, H. Fischer, A. Girard, S. R. Drayson, W. F. J. Evans, and J. E. Harries, Validation of water vapor results measured by the limb infrared monitor of the stratosphere experiment on Nimbus $7, J$ Geophys. Res., 89, 5115-5124, 1984a.
Russell, J. M., III, J. C. Gille, E. E. Remsberg, L. L. Gordley, P. L. Bailey, S. R. Drayson, H. Fischer, A. Girard, J. E. Harries, and W. F. J. Evans, Validation of nitrogen dioxide results measured by the limb infrared monitor of the stratosphere (LIMS) experiment on Nimbus 7, J. Geophys. Res., 89, 5099-5107, $1984 b$.

Solomon, P. M., R. de Zafra, A. Parrish, and J. W. Barrett, Diurnal variation of stratospheric chlorine monoxide: A critical test of chlorine chemistry in the ozone layer, Science, 224, 1210-1214, 1984.

Solomon, S., and R. R. Garcia, On the distributions of long-lived tracers and chlorine species in the middle atmosphere, $J$. Geophys. Res., 89, 11633-11644, 1984.

Solomon, S., H. S. Johnston, M. Kowalczyk, and I. Wilson, Instantaneous global ozone balance including observed nitrogen dioxide, Pure Appl. Geophys., 118, 58-85, 1980.

Solomon, S., D. W. Rusch, R. J. Thomas, and R. S. Eckman, Comparison of mesospheric ozone abundances measured by the solar mesosphere explorer and model calculations, Geophys. Res. Lett., $10,249-252,1983$

Stolarski, R. S., and R. J. Cicerone, Stratospheric chlorine: A possible sink for ozone, Can. J. Chem., 52, 1610-1615, 1974.

Turco, R. P., and R. C. Whitten, A note on the diurnal averaging of aeronomical models, J. Atmos. Terr. Phys., 40, 13-20, 1978.

Weinstock, E. M., M. J. Phillips, and J. G. Anderson, In situ observations of $\mathrm{ClO}$ in the stratosphere: A review of recent results, $J$ Geophys. Res., 86, 7273-7278, 1981.

Wofsy, S. C., Temporal and latitudinal variations of stratospheric trace gases: A critical comparison between theory and experiment, J. Geophys. Res., 83, 364-378, 1978.

Wofsy, S. C., and M. B. McElroy, $\mathrm{HO}_{x}, \mathrm{NO}_{x}$, and $\mathrm{ClO}_{x}$ : Their role in atmospheric photochemistry, Can. J. Chem., 52, 1582-1591, 1974.

World Meteorological Organization, The stratosphere 1981: Theory and measurements, Rep. 11, Global Ozone Res. and Monit. Proj., Geneva, Switzerland, 1982.

C. H. Jackman, J. A. Kaye, and R. S. Stolarski, Atmospheric Chemistry and Dynamics Branch, Code 616, NASA Goddard Space Flight Center, Greenbelt, MD 20771.

(Received April 4, 1985; revised August 16, 1985; accepted August 19, 1985.) 